\title{
An integrated multi-period planning of the production and transportation of multiple petroleum products in a single pipeline system
}

\author{
Alberto Herrán $^{\mathrm{a}^{*}}$, Fantahun M. Defersha ${ }^{\mathrm{b}},{\text { Mingyuan } \text { Chen }^{\mathrm{c}} \text { and Jesús M. de la Cruz }}^{\mathrm{d}}$ \\ ${ }^{a}$ Department of Computer Science Engineering, CES Felipe II, Complutense University, 28300 Aranjuez, Madrid, SPAIN \\ ${ }^{b}$ School of Engineering, University of Guelph, 50 Stone Road East, N1G 2W1 Guelph, Ontario, CANADA \\ ${ }^{c}$ Department of Mechanical and Industrial Engineering, Concordia University, H3G 1M8 Montreal, Quebec, CANADA
}

${ }^{d}$ Department of Computer Architecture and Automatic Control, Complutense University, 28040 Madrid, SPAIN

\begin{tabular}{|c|c|}
\hline$\overline{A R T I C L E I N F O}$ & A B S T RA C T \\
\hline $\begin{array}{l}\text { Article history: } \\
\text { Received 1 August } 2010 \\
\text { Received in revised form } \\
\text { 21 September } 2010 \\
\text { Accepted } 28 \text { September } 2010 \\
\text { Available online } \\
\text { 28 September } 2010 \\
\text { Keywords: } \\
\text { Multiproduct pipeline } \\
\text { Production } \\
\text { Transportation } \\
\text { Planning and scheduling } \\
\text { Multi-period model }\end{array}$ & $\begin{array}{l}\text { A multiproduct pipeline provides an economic way to transport large volumes of refined } \\
\text { petroleum products over long distances. In such a pipeline, different products are pumped } \\
\text { back-to-back without any separation device between them. The sequence and lengths of such } \\
\text { pumping runs must be carefully selected in order to meet market demands while minimizing } \\
\text { pipeline operational costs and satisfying several constraints. The production planning and } \\
\text { scheduling of the products at the refinery must also be synchronized with the transportation in } \\
\text { order to avoid the usage of the system at some peak-hour time intervals. In this paper, we } \\
\text { propose a multi-period mixed integer nonlinear programming (MINLP) model for an optimal } \\
\text { planning and scheduling of the production and transportation of multiple petroleum products } \\
\text { from a refinery plant connected to several depots through a single pipeline system. The } \\
\text { objective of this work is to generalize the mixed integer linear programming (MILP) } \\
\text { formulation proposed by Cafaro and Cerdá (2004, Computers and Chemical Engineering) } \\
\text { where only a single planning period was considered and the production planning and } \\
\text { scheduling was not part of the decision process. Numerical examples show how the use of a } \\
\text { single period model for a given time period may lead to infeasible solutions when it is used for } \\
\text { the upcoming periods. These examples also show how integrating production planning with the } \\
\text { transportation and the use of a multi-period model may result in a cost saving compared to } \\
\text { using a single-period model for each period, independently. }\end{array}$ \\
\hline
\end{tabular}

(c) 2010 Growing Science Ltd. All rights reserved.

\section{Introduction}

Pipelines have been a widely used mode of transportation for petroleum products and their derivatives for the last 40 years. The annual transportation cost in the petroleum industry usually surpasses billions of dollars, since large volumes have to be transported over long distances. Evidently, pipeline systems play an important role in the industry. Although the initial capital investment required to setup these transportation systems is high, the operating costs are very low

* Corresponding author. Tel.: 918099200 ext. 340 - Fax: 918099205

E-mail addresses: aherrang@fis.ucm.es (Alberto Herrán) 
comparing with other transportation modes such as rail and highway. The final price of the product depends on its transportation cost, making the optimization of the transportation process a problem of extreme relevance. Consequently, the related scheduling activities for product distribution using pipeline systems have been a focus for over 30 years. The simplest pipeline has one source, one destination, and one type of product to be delivered, e.g. the pipelines used in the transportation of crude oil from coastal ports to inland refineries. At the next level of complexity, the pipeline could have multiple destinations; and a more realistic pipeline would also handle multiple petroleum products treated in refineries such as kerosene, naphtha, gas oil, etc. (Sasikumar et al., 1997). These multiproduct pipelines are commonly named polyducts. In a polyduct, different products are pumped back-to-back without any separation devices as shown in Fig.1.

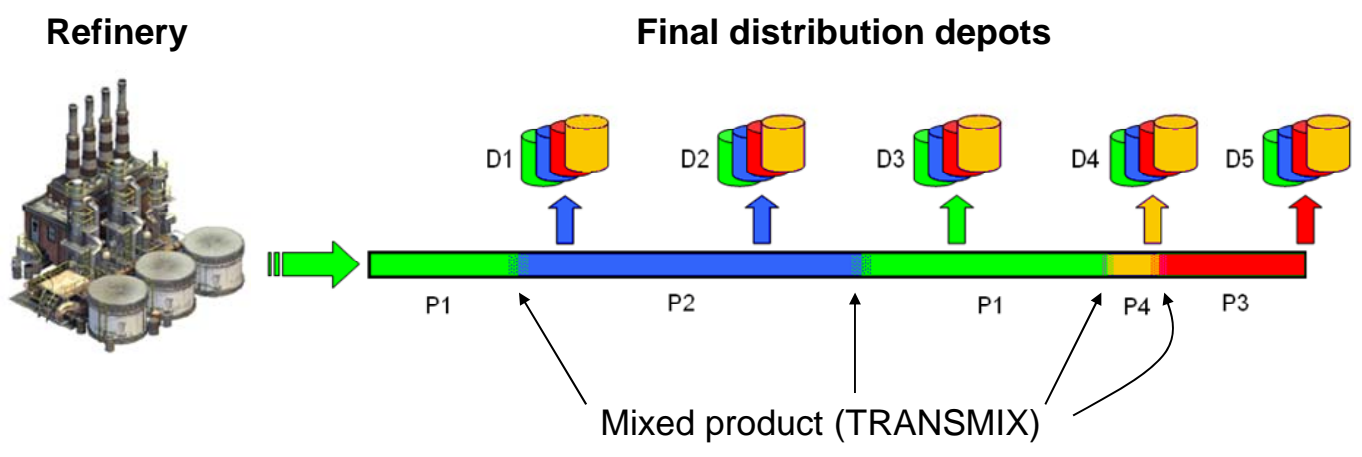

Fig. 1. Typical operation of a polyduct system

The main challenge in operating polyduct systems is planning the optimal sequence, length and starting time of each pumping run from the refinery to the pipeline, together with the optimal timing of transferring these products from the pipeline to each depot. Since there is no physical separation among different products as they move through the pipeline, some mixing (transmixes) and consequent contamination at product interface is inevitable. These transmixes must pass through a special treatment that usually involves sending them back to a refinery for reprocessing which increases the overall cost, significantly (Techo \& Holbrook, 1974). Moreover, if two products are known to generate high interface losses, the pipeline schedule must not place them adjacently. Another consequence of transmixes is that pumping small amount of products is not economical. Hence, each pumping run must fulfill a minimum length to make the pumping schedule efficient. The pumping schedule must also take into account the product availability at the refinery and the consumption of different products at each depot. The selection of the entry times of the slugs to the pipeline must be chosen to avoid high electrical energy cost intervals (pick-hours) while at the same time ensuring timely delivery of the products to depots.

A few papers on this subject have been published in the last decade. Existing approaches can be summarized in two groups attending to two fundamental criteria: (a) the type of pipeline system considered (a single pipeline system, or a pipeline network), and (b) the technique used to solve the proposed models (classical, heuristic, or hybrid methods). In both cases, given the complexity of the problem, most authors always introduce some simplification, either topological, relative to the system dimensions, to the length of the planning horizon, or relative to the way that the system is operated. Regarding to the authors who deal with a single pipeline system, some of them treat the time as a discrete variable. Based on this discrete approach, Rejowski and Pinto (2003) proposed an MILP formulation whose objective function is the sum of the pumping cost, inventory costs and the reprocessing cost associated with transmixes. They proposed two different models depending on whether the product contained in one section of the polyduct can simultaneously feed its corresponding depot and the next polyduct section or not. In both models, the amount of product pumped to the polyduct must be a multiple of certain volume. With this formulation, the cost associated with the generation of transmixes is not a function of realistic parameters. Rejowski and 
Pinto (2004) improved their previous work by adding additional constraints to perform a better calculation of the cost associated with the generation of a transmixes. Moreover, they incorporated some constraints relative to the minimum number of periods that each section must remain operative to guarantee the fulfillment of demand at each terminal. The model was applied, under several demand scenarios, to a system composed by a polyduct which takes different petroleum products from a single refinery and distribute them over five terminals located along its route. Additionally, Rejowski and Pinto (2008) developed a novel continuous-time representation to model the same process considered in their previous papers. Magatao et al. (2004) proposed another discrete approach to solve a model applied on a real world pipeline, which connects an inland refinery to a harbor, conveying different types of products. Cafaro and Cerdá (2003) formulated a model based on a continuous time approach. Rejowski and Pinto (2003) tried to diminish the costs associated with pumping and inventory costs associated with the transmixes. Since their approach was continuous, they did not make any hypothesis on the size of the slugs injected in the polyduct and considered it as a continuous variable. The model was applied over the same system considered by Rejowski and Pinto $(2003,2004)$. The results were better than the work by Rejowski and Pinto $(2003,2004)$ in terms of CPU time reduction. Cafaro and Cerdá (2004) improved their previous work by adding more constraints related to the existence of forbidden product sequences. Moreover, a more rigorous treatment of the pumping costs was made, and some additional redundant constraints were incorporated to the model in order to speed up the branch-and-bound solution algorithm. The authors extended their model to include dynamic scheduling over rolling planning horizon in Cafaro and Cerdá (2008). Recently, Mirhassani and Ghorbanalizadeh (2008) developed an integer programming formulation to deal with the same problem.

There are other works to solve problems topologically more complexes. De Felice and Charles (1975) described the use of a simulator to obtain the optimal sequence for the pumping of new products into a network composed by two sources, three intermediate pump stations, seven terminals and twelve polyducts connecting all these elements. Hane and Ratliff (1993) used a directed graph acyclic to represent the polyduct, in which nodes represent sources and terminals and arcs represent different polyduct sections. The direction of each arc determines the sense of the flow throughout the corresponding section, without the possibility of considering reversible sections. Campognara and De Souza (1996) also used a directed graph representation and considered reversible polyduct sections, limited storage capacity at terminals and forbidden product sequences. Camacho et al. (1990) studied polyduct networks with several terminals and ramifications where the objective was not to program the shipments through the polyduct, but to obtain the optimal operation over the pumping equipment installed in order to diminish the electrical cost dealing with the product delivery dates at each terminal. De la Cruz et al. (2003) proposed the most complex problem found in literature from the topological point of view. The pipeline network is composed by several sources (refineries, ports or storage centers), destinations (terminal depots from which the final distribution is performed by trucks) and intermediate nodes to store product. De la Cruz et al. (2004, 2005) extended their previous work by developing an MINLP model. After the linearization of some nonlinear constraints, they proposed a hybrid algorithm to solve it, based on the use of classical and heuristic methods. Other authors choose heuristic methods instead of exact methods to perform the search of the solution. Sasikumar (1997) proposed a heuristic to find a feasible solution. Also, Mildilú et al. (2002) used a heuristic method to get a near-optimal solution attending to the sum of the costs due to the penalties by delay in the deliveries and the costs associated with the shutdowns and starting of the pipeline. Finally, de la Cruz et al. $(2003,2004,2005)$ proposed a genetic algorithm (GA) to solve large-scale models based on a discrete time approach over polyduct networks.

The papers reviewed above consider the scheduling of the pumping operations of multiple products for a single planning period. However, similar to other manufacturing and distribution problems, production and distribution of refined petroleum products are also subject to recurring scheduling problems over multiple periods where a single period may be few days, weeks or months. In such 
situations, demands for different products need to be satisfied during the operating period. In these cases, the use of a single-period model repeatedly to solve a multiple period problem may lead to infeasible solutions. Since the demand for the upcoming periods are not considered in the optimization process, the solution tends to use more available inventory to satisfy the current demands rather than requiring new pumping operations. Thus, when we use the model for the upcoming period, the solution may be infeasible as it is impossible to satisfy the demands due to the delay in product delivery and minimum inventory. Whenever feasible solutions are possible by using a set of single-period models independently for a multi-period problem, the combined optimal costs are higher than solving the multi-period model, directly. However, according to Forrest and Oettli (2003), most of the oil industries operate their upstream operations, refining, and transportation groups as completely separate entities and integrating certain functions may be required for a better performance of the system. The production planning and scheduling of the products at the refinery must also be synchronized with the transportation to avoid pumping during high energy cost intervals. Based on the above considerations and the single period MILP model developed in Cafaro and Cerdá (2004), we propose a multi-period model for planning pumping operations of multiple products from a single source to multiple destinations which also integrates the production planning with transportation in order to reduce the operational cost of the system. This work improves our previous work in Defersha et al. (2008) in the following aspects:

- The objective function is modified in order to improve the estimation of the inventory levels at refinery.

- The linearization procedure of the MINLP model is elaborated (see Appendix I)

- Additional sets of constraints are provided to speed up the convergence of the branch and bound algorithm (see Appendix II).

- The numerical example is expanded to provide detailed analysis of results.

The remainder of this paper is organized as follows. Problem description and the developed model together with the nomenclature used in this paper are presented in details in Section 2. In Section 3, the proposed MINLP model is illustrated by solving a large-scale product pipeline scheduling problem involving two periods under several scenarios. Conclusions are shown in Section 4. Finally, an Appendix shows some constraints related to the linearization process used over the proposed MINLP model, together with an additional set of constraints to speed up the convergence of the branch and bound algorithm.

\section{Problem description}

A petroleum refinery facility produces and distributes different petroleum products to several depots through a single pipeline. Demands for various products at the depots must be satisfied in successive planning periods. Demands are based on forecasts and/or customer orders. Inventory levels both in the refinery and depot tanks must be kept within permissible ranges. Given the following information:

- the sequence of slugs in transit along the pipeline and their actual volumes at the beginning of the first period,

- product inventories available at the refinery and the depot tanks at the beginning of the first period,

- maximum values for the slug pump rate, the product supply rate from the pipeline to depots and the product delivery rate from depots to local markets,

- the length of each planning period,

the problem goal is to establish the optimal production plan and schedule for all the products, sequence of new slug injections in the pipeline together with their initial volumes, and the product assigned to each one in order to: (1) meet product demands at each depot during each period; (2) keep inventory levels in the refinery and depot tanks within the permissible range; and (3) minimize the 
delivery cost of products to depots, pumping cost, interface losses, and inventory carrying costs. At the same time, variations in sizes and coordinates of the slugs as they move along the pipeline as well as the changes of inventory levels in refinery and depot tanks are tracked over each planning period. Moreover, forbidden sequences must be avoided when planning the sequence of the pumping operations. In order to solve this problem it is necessary to develop a mathematical model composed of an objective function and a set of constraints. Next sections show all these equations using the nomenclature defined in this paper, resulting in an MILP that can be solved with any commercial solver. All the equations of the model can be grouped on the following subsets:

(1) Objective function

(2) Production planning

(3) Pumping of new slugs into the pipeline

(4) Location of each slug pumped into the pipeline

(5) Volume of product transferred from slugs to depots

(6) Fulfillment of market demands

(7) Control of inventories in refinery tanks

(8) Control of inventories in depot tanks

\subsection{Nomenclature}

Sets:

Set of time periods in the planning horizon indexed by $t=1 \ldots T$

Set of refined petroleum products indexed by $p=1, \ldots, P$

$J \quad$ Set of distribution terminal depots along the pipeline indexed by $j=1, \ldots, J$

$K \quad$ Set of peak-hour intervals in any time period indexed by $k=1, \ldots, K$

$R \quad$ Set of potential production runs of a given product in any time period indexed by $1, \ldots, R$

$I \quad$ Set of potential slugs to be pumped in any time period indexed by $i=1, \ldots, I$

$O \quad$ Set of old slugs in the pipe line at the beginning of the planning horizon indexed by $o=1, \ldots, O$

$\mathrm{S} \quad$ Set of product pairs $\left\{\left(p, p^{\prime}\right), \ldots\right\}$ representing forbidden pumping sequences

Parameters:
$\operatorname{cid}_{p, j}$
Unit inventory cost of product $p$ at depot $j$
$\operatorname{cir}_{p}$
Unit inventory cost of product $p$ at refinery tanks
$c f_{p, p}$
Unit reprocessing cost of interface material involving products $p$ and $p$ '
$c p_{p, j}$
Unit pumping cost to deliver product $p$ from the refinery to depot $j$
$\rho_{k, t}$
Unit penalty cost for pipeline operation during the peak-hour interval $k$ of period $t$
$I P H_{k, t} \quad$ Lower limit of the $k^{\text {th }}$ peak-hour interval of period $t$
$F P H_{k, t} \quad$ Upper limit of the $k^{\text {th }}$ peak-hour interval of period $t$
hmax Length of a time period $t$ (each time period is assumed to be of equal length)
$I D 0_{p, j} \quad$ Inventory level of product $p$ at depot $j$ at the beginning of the planning horizon
$I F_{p, p} \quad$ Interface volume between consecutively pumped slugs containing products $p$ and $p$ '
$I R O_{p} \quad$ Inventory level of product $p$ at refinery tanks at the beginning of the planning horizon
$I R \min _{p} \quad$ Minimum allowed inventory level of product $p$ at refinery tanks
$I R \max _{p} \quad$ Maximum allowed inventory level of product $p$ at refinery tanks
PRmin Minimum allowable length of a production run
Imin Minimum time length of a new slug pumped into the pipeline 
Imax Maximum time length of a new slug pumped into the pipeline

$q d_{p, j, t} \quad$ Overall demand of product $p$ to be satisfied at $\operatorname{depot} j$ in period $t$

$v m \quad$ Maximum supply rate to the local market

vbmin Minimum pumping rate of slugs into the pipeline

vbmax Maximum pumping rate of slugs into the pipeline

$W 0_{o} \quad$ Size of the old slug $o$ at the beginning of the planning horizon

$W I F 0_{o} \quad$ Interface volume between old slug $o$ and $o-1$

$\mathrm{FO}_{o} \quad$ Upper coordinate of old slug $o$ at the beginning of the planning horizon

$y o_{o, p} \quad$ Parameter denoting if an old slug $o$ contains product $p$

$\sigma_{j} \quad$ Volumetric coordinate of depot $j$ from the refinery

$\tau_{p, p} \quad \quad$ Changeover time between injections of products $p$ and $p$ '

$v r_{p} \quad$ Production rate of product type $p$

Continuous variables:

$L R_{r, p, t} \quad$ Time length of the $r^{\text {th }}$ production run of product $p$ in period $t$

$C R_{r, p, t} \quad$ Completion time of the $r^{\text {th }}$ production run of product $p$ in period $t$

$L_{i, t} \quad$ Time length of the $i^{t h}$ slug pumped in period $t$

$C_{i, t} \quad$ Completion time of the $i^{\text {th }}$ slug pumped in period $t$

$A_{p, i, t} \quad$ Volume of product $p$ injected in the pipeline while pumping the $i^{\text {th }}$ slug in period $t$

$D o_{o, j, i, t} \quad$ Volume of the old slug $o$ transferred from the pipeline to depot $j$ while pumping the $i^{\text {th }}$ slug in period $t$

$D V o_{o, p, j, i, t} \quad$ Volume of product $p$ transferred to depot $j$ from the old slug $o$ while pumping the $i^{\text {th }}$ slug in period $t$

$D_{i, t, j, i^{\prime}, t^{\prime}} \quad$ Volume of the $i^{\text {th }}$ slug pumped in period $t$ transferred from the pipeline to depot $j$ while pumping slug $i^{\prime}$ in period $t^{\prime} \geq t$

$D V_{i, t, p, j, i^{\prime}, t}$, Volume of product $p$ transferred to depot $j$ from $i^{\text {th }}$ slug pumped in period $t$ while pumping slug $i^{\prime}$ in period $t^{\prime} \geq t$

$F o_{o, i, t} \quad$ Upper coordinate of old slug $o$ at time $C_{i, t}$

$F_{i, t, i, t} \quad \quad$ Upper coordinate of the $i^{\text {th }}$ slug pumped in period $t$ from the refinery at time $C_{i^{\prime}, t}$,

$H_{i, t, k} \quad$ Portion of $L_{i, t}$ pumped within the $k^{\text {th }}$ peak-hour time interval in period $t$

$I D_{p, j, i, t} \quad$ Inventory level of product $p$ in $\operatorname{depot} j$ at time $C_{i, t}$

$I R S_{p, i, t} \quad$ Inventory level of product $p$ in refinery at time $C_{i, t}-L_{i, t}$

$I R F_{p, i, t} \quad$ Inventory level of product $p$ in refinery at time $C_{i, t}$

$N_{t} \quad$ Current number of slugs pumped in period $t$

$q l_{r, p, i, t} \quad$ Volume of the $r^{\text {th }}$ production run of product $p$ in period $t$ available at time $C_{i, t}-L_{i, t}$

$q u_{r, p, i, t} \quad$ Volume of the $r^{\text {th }}$ production run of product $p$ in period $t$ available at time $C_{i, t}$

$q m_{p, j, i, t} \quad$ Volume of product $p$ transferred to depot $j$ during the time interval $\left(C_{i-1, t}, C_{i, t}\right)$

$Q_{i, t} \quad$ Original volume of the $i^{\text {th }}$ slug pumped in period $t$

$W o_{o, i, t} \quad$ Volume of the slug $o$ in period $t$ at time $C_{i, t}$

$W_{i, t, i^{\prime}, t}, \quad$ Volume of the $i^{\text {th }}$ slug pumped in period $t$ at time $C_{i, t}$,

$W I F_{i, t, p, p} \quad$ Interface volume between slugs $i$ and $i-1$ in period $t$ if they contain products $p$ and $p$ ' 
Binary variables:

$\begin{array}{ll}u_{i, t, k} & \text { Variable denoting that } i^{\text {th }} \text { slug pumped in period } t \text { starts after } I P H_{k, t} \\ v_{i, t, k} & \text { Variable denoting that } i^{\text {th }} \text { slug pumped in period } t \text { ends before } F P H_{k, t} \\ x o_{o, j, i, t} & \text { Variable denoting that a portion of the old slug } o \text { can be transferred to depot } j \text { while the } \\ & i^{t h} \text { slug is pumped in period } t \\ x_{i, t, j, i, t^{\prime},} & \text { Variable denoting that a portion of the } i^{t h} \text { slug pumped in period } t \text { can be transferred to } \\ & \text { depot } j \text { while pumping the slug } i \text { ' in period } t^{\prime} \\ y_{i, t, p} & \text { Variable denoting that the } i^{t h} \text { slug pumped in period } t \text { contains product } p \\ y l_{t, p} & \text { Variable denoting that the last slug pumped in period } t \text { contains product } p \\ y p_{r, p, t} & \text { Variable denoting that } r^{\text {th }} \text { production run of product } p \text { in period } t \text { is performed } \\ z l_{r, p, i, t} & \text { Variable denoting that the } i^{\text {th }} \text { slug pumped in period } t \text { starts before the } r^{\text {th }} \text { refinery } \\ & \text { production run of product } p \text { has ended } \\ z u_{r, p, i, t} & \text { Variable denoting that the } i^{\text {th }} \text { slug pumped in period } t \text { ends after the } r^{t h} \text { refinery } \\ & \text { production run of product } p \text { has started }\end{array}$

\subsection{Objective function}

The objective function of the model is given in Eq. (1) and comprises five different terms. The first and the second terms are the pumping costs at daily normal and peak-hours time intervals, respectively. The third term is the cost of reprocessing the interface material between consecutive slugs. The last two terms stand for the cost of holding product inventory in refinery and depot tanks, respectively. These two terms are based on an average of product inventory levels at the time instants when new slugs are pumped into the polyduct. Since the proposed model of this paper also integrates the production planning as a decision variable, the fourth term (inventory cost at refinery tanks) differs from the proposed one by Cafaro and Cerdá (2004). Moreover, this term, is also modified over the proposed one at Defersha et al. (2008) in order to improve the estimation of the inventory levels at refinery. The production at refinery along the time interval $\left[t \times \operatorname{hmax}-\left(C_{I, t}-L_{I, t}\right)\right]$ is added to the inventory level at the beginning of the last pumping rung at period $t$.

$$
\begin{aligned}
\min z= & \sum_{p=1}^{P} \sum_{j=1}^{J}\left(c p_{p, j} \times \sum_{i=1}^{I} \sum_{t=1}^{T}\left(\sum_{o=1}^{O} D V o_{o, p, j, i, t}+\sum_{i^{\prime}=1}^{I} \sum_{t^{\prime}=1}^{T} D V_{i, t, j, i^{\prime}, t^{\prime}}\right)\right)+ \\
& \sum_{i=1}^{I} \sum_{t=1}^{T} \sum_{k=1}^{K} \rho_{t, k} \times H_{i, t, k}+ \\
& \sum_{i=1}^{I} \sum_{t=1}^{T} \sum_{p=1}^{P} \sum_{p^{\prime}=1}^{P} c f_{p, p^{\prime}} \times W I F_{i, t, p, p^{\prime}}+ \\
& \sum_{t=1}^{T}\left(\sum_{p=1}^{P} c i r_{p} \times \frac{h m a x}{(I+1)} \cdot\left(\sum_{i=1}^{I} I R S_{p, i, t}+\left(I R S_{p, I, t}+\sum_{r=1}^{R}\left(v r_{p} \cdot L R_{r, p, t}-q u_{I, t, r, p}\right)\right)\right)+\right. \\
& \sum_{t=1}^{T}\left(\sum_{p=1}^{P} \sum_{j=1}^{J} c i d_{p, j} \times \frac{h m a x}{I} \cdot\left(\sum_{i=1}^{I} I D_{p, j, i, t}\right)\right)
\end{aligned}
$$

\subsection{Production planning}

Constraint in Eq. (2) states that the $r^{\text {th }}$ production of a given product $p$ in a given time period $t$ must begin and end within the time limits of the period $t$. The production runs of different product types can be performed concurrently and discharged to their respective designated refinery tanks, while the production runs for a given product type $p$ are chronologically ordered. This chronological order is enforced using Eq. (3). By other hand, the actual number of production runs of a given product to be performed in any time period is not known in advance. However, at optimal solution, only a certain 
numbers of the first runs will be actually performed as enforced by the constraints shown in Eqs. (4) and (5), where $M_{1}$ is a relatively large number, which can be set to $1.1 \times h \max$. Finally, the constraint shown in Eq. (6) states that a production run of a given product must be longer than the minimum allowable duration whenever it is performed.

$$
\begin{aligned}
& (t-1) \cdot h \max \leq C R_{r, p, t}-L R_{r, p, t} \leq C R_{r, p, t} \leq t \cdot h \max \quad ; \quad \forall(r, p, t) \\
& C R_{r, p, t}-L R_{r, p, t} \geq C R_{r-1, p, t} \quad ; \quad \forall(r, p, t): r>1 \\
& y p_{r, p, t} \leq y p_{r-1, p, t} \quad ; \quad \forall(r, p, t): r>1 \\
& L R_{r, p, t} \leq M_{1} \cdot y p_{r, p, t} \quad ; \quad \forall(r, p, t) \\
& C R_{r, p, t} \geq y p_{r, p, t} \cdot P R \min \quad ; \quad \forall(r, p, t)
\end{aligned}
$$

\subsection{Pumping of new slugs into the pipeline}

Eq. (7) states that the $i^{\text {th }}$ pumping run in period $t$ must also end within the time limits of that period. A single product can be assigned to a slug flowing inside the pipeline by Eq. (8). The pumping of a new slug to the pipeline should never start before completing the pumping of the preceding slug and the subsequent changeover operation. This constraint is enforced using Eq. (9a) if the two sequence slugs are pumped within the same period $t$, or by Eq. (9b) for the last slug at $t-1$ followed by the first slug at period $t$. The volume of the $i^{\text {th }}$ slug pumped in the pipeline in period $t$ is limited by Eq. (10). Moreover, the length of slug $i$ in any period $t$ is also limited by Eq. (11). The actual number of slugs to be pumped in any time period is not known in advance which is similar to what we had in production runs. However, at the optimal solution, the first few or more slugs will be actually pumped as shown in Eq. (12).

$$
\begin{aligned}
& (t-1) \cdot h \max \leq C_{i, t}-L_{i, t} \leq C_{i, t} \leq t \cdot h \max ; \quad \forall(i, t) \\
& \sum_{p=1}^{P} y_{i, t, p} \leq 1 ; \forall(i, t) \\
& C_{i, t}-L_{i, t} \geq C_{i-1, t}+\tau_{p, p^{\prime}} \cdot\left(y_{i-1, t, p}+y_{i, t, p^{\prime}}-1\right) ; \quad \forall\left(i, t, p, p^{\prime}\right): i>1 \\
& C_{1, t}-L_{1, t} \geq C_{1, t-1}+\tau_{p, p^{\prime}} \cdot\left(y l_{t-1, p}+y_{1, t, p^{\prime}}-1\right) ; \quad \forall\left(t, p, p^{\prime}\right): t>1 \\
& v b \min \cdot L_{i, t} \leq Q_{i, t} \leq v \max \cdot L_{i, t} ; \forall(i, t) \\
& \left(\sum_{p=1}^{P} y_{i, t, p}\right) \cdot \operatorname{lmin} \leq L_{i, t} \leq\left(\sum_{p=1}^{P} y_{i, t, p}\right) \cdot \operatorname{lmax} ; \forall(i, t) \\
& \sum_{p=1}^{P} y_{i, t, p} \leq \sum_{p=1}^{P} y_{i-1, t, p} ; \forall(i, t): i>1
\end{aligned}
$$

In order to extend the proposed model by Cafaro and Cerdá (2004) to several periods, it is necessary to include an additional set of constraints to measure the exact number of new slugs that are really pumped into the polyduct at each period. This number is given by Eq. (13). The type of the product contained in the slug actually pumped at last in period $t$ is determined from the value of the binary variable $y l_{t, p}$, which is determined by using Eq. (14) and Eq. (15). The volume of interface material between consecutive slugs is calculated by Eqs. (16). Moreover, because of product contamination, there are some forbidden product sequences which can be avoided by Eqs. (17), where $S$ is the set of forbidden product sequences $\left(p, p^{\prime}\right)$.

$$
\begin{aligned}
& N_{t}=\sum_{i=1}^{I} \sum_{p=1}^{P} y_{i, t, p} \quad ; \quad \forall t \\
& y l_{t, p} \geq 1+i \cdot y_{i, t, p}-N_{t} \quad ; \quad \forall(i, t, p)
\end{aligned}
$$


$\sum_{p=1}^{P} y l_{t, p} \leq 1 \quad ; \quad \forall t$

$W I F_{i, t, p, p^{\prime}} \geq I F_{p, p^{\prime}} \cdot\left(y_{i-1, t, p}+y_{i, t, p^{\prime}}-1\right) \quad ; \quad \forall\left(i, t, p, p^{\prime}\right): i>1$

$W I F_{1, t, p, p^{\prime}} \geq I F_{p, p^{\prime}} \cdot\left(y l_{t-1, p}+y_{1, t, p^{\prime}}-1\right) \quad ; \quad \forall\left(t, p, p^{\prime}\right): t>1$

$W I F_{1,1, p, p^{\prime}} \geq I F_{p, p^{\prime}} \cdot\left(y o_{O, p}+y_{1,1, p^{\prime}}-1\right) \quad ; \quad \forall\left(p, p^{\prime}\right)$

$y_{i-1, t, p}+y_{i, t, p^{\prime}} \leq 1 \quad ; \quad \forall(i, t): i>1 \quad ; \quad\left(p, p^{\prime}\right) \in S$

$y l_{t-1, p}+y_{1, t, p^{\prime}} \leq 1 \quad ; \quad \forall t: t>1 \quad ; \quad\left(p, p^{\prime}\right) \in S$

$y o_{O, p}+y_{1,1, p^{\prime}} \leq 1 \quad ; \quad ; \quad\left(p, p^{\prime}\right) \in S$

Finally, there are an additional set of constraints to calculate the portion of slug $i$ in period $t$ pumped into the pipeline within the $k^{\text {th }}$ peak-hour interval of that period, $H_{i, t, k}$. The four constraints shown in Eq. (18) are required to set the values of all the binary variables $u_{i, t, k}$ and $v_{i, t, k}$.

$$
\begin{array}{ll}
C_{i, t}-L_{i, t} \geq I P H_{k, t} \cdot u_{i, t, k} & ; \quad \forall(i, t, k) \\
C_{i, t}-L_{i, t} \leq I P H_{k, t}+u_{i, t, k} \cdot M_{1} & ; \quad \forall(i, t, k) \\
C_{i, t} \leq F P H_{k, t}+\left(1-v_{i, t, k}\right) \cdot M_{1} & ; \quad \forall(i, t, k) \\
C_{i, t} \geq F P H_{k, t} \cdot\left(1-v_{i, t, k}\right) & ; \quad \forall(i, t, k)
\end{array}
$$

Now, given the four combinations of these two binary variables, four cases should be considered depending on if slug $i$ pumped into the pipeline in period $t$, within the $k^{\text {th }}$ peak-hour interval of that period, starts or not after $I P H_{k, t}$, and ends or not before $F P H_{k, t}$ :

(a) $u_{i, t, k}=0$ and $v_{i, t, k}=0$ : If the pumping of slug $i$ in period $t$ starts before and ends after the $k^{t h}$ peak-hour interval, the constraint needed to calculate the right value of $H_{i, t, k}$ is:

$$
H_{i, t, k}=F P H_{k, t}-I P H_{k, t} \quad ; \quad \forall(i, t, k)
$$

(b) $u_{i, t, k}=0$ and $v_{i, t, k}=1$ : In this case, just the ending time of the pumping of slug $i$ in period $t$ is inside the $k^{\text {th }}$ peak-hour interval and there can be two different instances depending on the value of $C_{i, t}$. If $C_{i, t}$ is smaller than $I P H_{k, t}$, the pumping of slug $i$ will occur outside the $k^{\text {th }}$ interval and $H_{i, t, k}=0$, otherwise, part of slug $i$ is pumped within the $k^{\text {th }}$ interval, and $H_{i, t, k}$ is calculated by:

$$
H_{i, t, k}=C_{i, t}-I P H_{k, t} \quad ; \quad \forall(i, t, k)
$$

(c) $u_{i, t, k}=1$ and $v_{i, t, k}=0$ : In this case, only the starting time of pumping slug $i$ in period $t$ is inside the $k^{\text {th }}$ peak-hour interval. Two instances can arise depending on when the pumping of slug $i$ begins. If $\left(C_{i, t}-L_{i, t}\right)$ is higher than $F P H_{k, t}$, then the pumping run is completely outside the $k^{\text {th }}$ peak-hour interval and $H_{i, t, k}=0$, otherwise:

$$
H_{i, t, k}=F P H_{k, t}-\left(C_{i, t}-L_{i, t}\right) \quad ; \quad \forall(i, t, k)
$$

(d) $u_{i, t, k}=1$ and $v_{i, t, k}=1$ : Finally, if the start time $\left(C_{i, t}-L_{i, t}\right)$ and the completion time $\left(C_{i, t}\right)$ for the pumping of slug $i$ in period $t$ both belong to $k^{\text {th }}$ peak-hour interval, the pumping run of slug $i$ is completely inside the $k^{\text {th }}$ peak-hour interval, and $H_{i, t, k}$ is calculated by:

$$
H_{i, t, k}=L_{i, t} \quad ; \quad \forall(i, t, k)
$$


One way to select the right constraint among the four previous cases to calculate the value of $H_{i, t, k}$ is to include into the model Eqs.(19)-(21). Since pipeline energy costs are to be minimized, at the optimum, the equation associated to cases (a)-(d) becomes Eqs.(19)-(22) respectively.

$$
\begin{aligned}
& H_{i, t, k} \geq F P H_{k, t}-I P H_{k, t}-u_{i, t, k} \cdot M_{1}-v_{i, t, k} \cdot M_{1} \quad ; \quad \forall(i, t, k) \\
& H_{i, t, k} \geq C_{i, t}-I P H_{k, t}-\left(1-v_{i, t, k}\right) \cdot M_{1}-u_{i, t, k} \cdot M_{1} ; \forall(i, t, k) \\
& H_{i, t, k} \geq F P H_{k, t}-\left(C_{i, t}-L_{i, t}\right)-\left(1-u_{i, t, k}\right) \cdot M_{1}-v_{i, t, k} \cdot M_{1} \quad ; \quad \forall(i, t, k) \\
& H_{i, t, k} \geq L_{i, t}+\left(u_{i, t, k}+v_{i, t, k}-2\right) \cdot M_{1} \quad ; \quad \forall(i, t, k)
\end{aligned}
$$

\subsection{Location of each slug pumped into the pipeline}

A set of constraints is necessary to calculate the upper coordinate of all the slugs into the pipeline. Eqs. (23) calculate the upper coordinate at time $C_{i, t}$ of the old slug $o<O$ and $o=O$, respectively. Eq. (24a) establishes a relationship between the upper coordinate at time $C_{i,}{ }^{\prime}$ ' of a new slug $i$ pumped in period $t$ and the next slug $i+1$ pumped in a different period $t>t$. Eq. (24b) is similar to Eq. (24a) but for a new slug $i=I$ pumped in period $t$ and immediately followed by the first slug pumped in period $t+1$. Eq. (24c) is to calculate the upper coordinate at time $C_{i, t}$ of the new slug $t<I$ which is immediately followed a later slug pumped in the same period as slug $i$. Eq. (24d) states that the upper coordinate of a slug just at the end of its pumping is equal to its volume at $C_{i, t}$.

$$
\begin{aligned}
& F o_{o, i, t}=F o_{o+1, i, t}+W o_{o, i, t} \quad ; \quad \forall(o, i, t): o<O \\
& F o_{O, i, t}=F_{1,1, i, t}+W o_{O, i, t} \quad ; \quad \forall(i, t) \\
& F_{i, t, i^{\prime}, t^{\prime}}=F_{i+1, t, i^{\prime}, t^{\prime}}+W_{i, t, i^{\prime}, t^{\prime}} \quad ; \quad \forall\left(i, t, i^{\prime}, t^{\prime}\right): i<I, t<t^{\prime} \\
& F_{I, t, i^{\prime}, t^{\prime}}=F_{1, t+1, i^{\prime}, t^{\prime}}+W_{I, t, i^{\prime}, t^{\prime}} \quad ; \quad \forall\left(t, i^{\prime}, t^{\prime}\right): t<t^{\prime}, t<T \\
& F_{i, t, i^{\prime}, t}=F_{i+1, t, i^{\prime}, t}+W_{i, t, i^{\prime}, t} \quad ; \quad \forall\left(i, t, i^{\prime}\right): i>i^{\prime} \\
& F_{i, t, i, t}=W_{i, t, i, t} \quad ; \quad \forall(i, t)
\end{aligned}
$$

\subsection{Volume of product transferred from slugs to depots}

This section shows the set of constraints used to calculate the volume of product transferred from slugs to depots. Constraints show in Eqs. (25) and (26) are used to calculate the volume transferred from an old slug $o$ and new slug $i$, respectively, to depots while pulping new slugs.

$$
\begin{array}{ll}
\sum_{j=1}^{J} D o_{o, j, i, t}=W o_{o, i-1, t}-W o_{o, i, t} & ; \quad \forall(o, i, t): i>1 \\
\sum_{j=1}^{J} D o_{o, j, 1, t}=W o_{o, I, t-1}-W o_{o, 1, t} & ; \quad \forall(o, t): t>1 \\
\sum_{j=1}^{J} D o_{o, j, 1,1}=W o_{O}-W o_{o, 1,1} & ; \quad \forall o \\
\sum_{j=1}^{J} D_{i, t, j, j, t^{\prime}}=W_{i, t, i^{\prime}-1, t^{\prime}}-W_{i, t, i^{\prime}, t^{\prime}} & ; \quad \forall\left(i, t, i^{\prime}, t^{\prime}\right): i^{\prime}>1, t<t^{\prime} \\
\sum_{j=1}^{J} D_{i, t, j, 1, t^{\prime}}=W_{i, t, I, t^{\prime}-1}-W_{i, t, 1, t^{\prime}} & ; \quad \forall\left(i, t, t^{\prime}\right): t<t^{\prime} \\
\sum_{j=1}^{J} D_{i, t, j, j, t}=W_{i, t, i^{\prime}-1, t}-W_{i, t, i^{\prime}, t} & ; \quad \forall\left(i, t, i^{\prime}\right): i<i^{\prime} \\
\sum_{j=1}^{J} D_{i, t, j, j, t}=Q_{i, t}-W_{i, t, i, t} & ; \quad \forall(i, t)
\end{array}
$$


There are also some feasibility conditions for transferring material from a slug to a depot. Eqs. (27) and (28) state that the transfer of material from a slug $s_{1}$ to a depot is feasible if and only if the outlet to the depot is reachable from this slug while pumping a later slug $s_{2}$. Moreover, the feasibility of material transfer from a slug $s_{1}$ while pumping a later slug $s_{2}$ to a depot $j$ requires two conditions: (a) the upper pipeline coordinate of the slug $s_{1}$ at the completion time of the ejection of a later slug $s_{2}$, decreased by the volume of the interface material for all $j<J$, should not be lower than the volumetric coordinate of the depot, fixed by Eqs. (29)-(32) where $M_{2}=1.1 \times v b \max \times h \max$, and (b) the lower coordinate of slug $s_{1}$ at the completion time of the pumping of the slug that immediately precedes slug $s_{2}$ must be less than the depot coordinate.

$$
\begin{aligned}
& D o_{o, j, i, t} \leq x o_{o, j, i, t} ; \quad \forall(o, j, i, t) \\
& D_{i, t, j, i^{\prime}, t^{\prime}} \leq M_{2} \cdot x_{i, t, j, i^{\prime}, t^{\prime}} \quad ; \quad \forall\left(i, t, j, i^{\prime}, t^{\prime}\right): t<t^{\prime} \\
& D_{i, t, j, i^{\prime}, t} \leq M_{2} \cdot x_{i, t, j, i^{\prime}, t} \quad ; \quad \forall\left(i, t, j, i^{\prime}\right): i \leq i^{\prime} \\
& F o_{o, i, t}-W I F 0_{o} \geq \sigma_{j} \cdot x o_{o, j, i, t} \quad ; \quad \forall(o, j, i, t): j<J \\
& F_{i, t, i^{\prime}, t^{\prime}}-\sum_{p=1}^{P} \sum_{p^{\prime}=1}^{P} W I F_{i, t, p, p^{\prime}} \geq \sigma_{j} \cdot x_{i, t, j, i^{\prime}, t^{\prime}} \quad ; \quad \forall\left(i, t, j, i^{\prime}, t^{\prime}\right): j<J, t<t^{\prime} \\
& F_{i, t, i^{\prime}, t}-\sum_{p=1}^{P} \sum_{p^{\prime}=1}^{P} W I F_{i, t, p, p^{\prime}} \geq \sigma_{j} \cdot x_{i, t, j, i^{\prime}, t} \quad ; \quad \forall\left(i, t, j, i^{\prime}\right): j<J, i \leq i^{\prime} \\
& F o_{o, i, t} \geq \sigma_{J} \cdot x o_{o, J, i, t} \quad ; \quad \forall(o, i, t) \\
& F_{i, t, i^{\prime}, t^{\prime}} \geq \sigma_{J} \cdot x_{i, t, J, i^{\prime}, t^{\prime}} \quad ; \quad \forall\left(i, t, i^{\prime}, t^{\prime}\right): t<t^{\prime} \\
& F_{i, t, i^{\prime}, t} \geq \sigma_{J} \cdot x_{i, t, J, i^{\prime}, t} \quad ; \quad \forall\left(i, t, i^{\prime}\right): i \leq i^{\prime}
\end{aligned}
$$

As stated previously, material can be transferred from a slug to a depot if the depot is reachable from the slug. However, there should be an upper bound on the volume of material that can be transferred from the slug to the depot. Eqs. (33) are to impose such an upper bound on material transfer from an old slug $o$ to a depot $j$, while the constraints in Eqs. (34) are similar to (33) but for the material transfer from new slugs to depots. Previously, it was stated a second feasibility condition, (b), for a transfer of material from a slug $s_{1}$ while pumping a later slug $s_{2}$ requires that the lower coordinate of slug $s_{1}$ at the completion time of the injection of the slug that immediately precedes slug $s_{2}$ must be less than the depot coordinate.

$$
\begin{array}{ll}
D o_{o, j, i, t} \leq \sigma_{j}-F o_{o+1, i-1, t}-\sum_{j^{\prime}=1}^{j-1} D o_{o, j^{\prime}, i, t}+\left(1-x o_{o, j, i, t}\right) \cdot M_{2} & ; \quad \forall(o, j, i, t): o<O, i>1 \\
D o_{O, j, i, t} \leq \sigma_{j}-F_{1,1, i-1, t}-\sum_{j^{\prime}=1}^{j-1} D o_{O, j^{\prime}, i, t}+\left(1-x o_{O, j, i, t}\right) \cdot M_{2} & ; \quad \forall(j, i, t): i>1 \\
D o_{O, j, 1, t} \leq \sigma_{j}-F_{1,1,1, t, 1}-\sum_{j^{\prime}=1}^{j-1} D o_{O, j^{\prime}, 1, t}+\left(1-x o_{O, j, 1, t}\right) \cdot M_{2} & ; \forall(j, t): t>1 \\
D o_{O, j, 1,1} \leq \sigma_{j}-\sum_{j^{\prime}=1}^{j-1} D o_{O, j^{\prime}, 1,1}+\left(1-x o_{O, j, 1,1}\right) \cdot M_{2} & ; \forall j \\
D o_{o, j, 1,1} \leq \sigma_{j}-F 0_{o+1}-\sum_{j^{\prime}=1}^{j-1} D o_{o, j^{\prime}, 1,1}+\left(1-x o_{o, j, 1,1}\right) \cdot M_{2} & ; \forall(o, j): o<O
\end{array}
$$




$$
\begin{array}{ll}
D_{i, t, j, i^{\prime}, t^{\prime}} \leq \sigma_{j}-F_{i+1, t, i^{\prime}-1, t^{\prime}}-\sum_{j^{\prime}=1}^{j-1} D_{i, t, j^{\prime}, i^{\prime}, t^{\prime}}+\left(1-x_{i, t, j, i^{\prime}, t^{\prime}}\right) \cdot M_{2} & ; \quad \forall\left(i, t, j, i^{\prime}, t^{\prime}\right): i<I, i^{\prime}>1, t<t^{\prime} \\
D_{I, t, j, i^{\prime}, t^{\prime}} \leq \sigma_{j}-F_{1, t+1, i^{\prime}-1, t^{\prime}}-\sum_{j^{\prime}=1}^{j-1} D_{I, t, j^{\prime}, i^{\prime}, t^{\prime}}+\left(1-x_{I, t, j, i^{\prime}, t^{\prime}}\right) \cdot M_{2} & ; \quad \forall\left(t, j, i^{\prime}, t^{\prime}\right): i^{\prime}>1, t<t^{\prime} \\
D_{I, t, j, 1, t^{\prime}} \leq \sigma_{j}-F_{1, t+1, I, t^{\prime}-1}-\sum_{j^{\prime}=1}^{j-1} D_{I, t, j^{\prime}, 1, t^{\prime}}+\left(1-x_{I, t, j, 1, t^{\prime}}\right) \cdot M_{2} & ; \quad \forall\left(t, j, t^{\prime}\right): t<t^{\prime}-1 \\
D_{I, t, j, 1, t+1} \leq \sigma_{j}-\sum_{j^{\prime}=1}^{j-1} D_{I, t, j^{\prime}, 1, t+1}+\left(1-x_{I, t, j, 1, t+1}\right) \cdot M_{2} & ; \quad \forall(t, j): t<T \\
D_{i, t, j, 1, t^{\prime}} \leq \sigma_{j}-F_{i+1, t, I, t^{\prime}-1}-\sum_{j^{\prime}=1}^{j-1} D_{i, t, j^{\prime}, 1, t^{\prime}}+\left(1-x_{i, t, j, 1, t^{\prime}}\right) \cdot M_{2} & ; \quad \forall\left(i, t, j, t^{\prime}\right): i<I, t<t^{\prime} \\
D_{i, t, j, i+1, t} \leq \sigma_{j}-\sum_{j^{\prime}=1}^{j-1} D_{i, t, j^{\prime}, i+1, t}+\left(1-x_{i, t, j, j+1, t}\right) \cdot M_{2} & ; \forall(i, t, j): i<I \\
D_{i, t, j, i^{\prime}, t} \leq \sigma_{j}-F_{i+1, t, i^{\prime}-1, t}-\sum_{j^{\prime}=1}^{j-1} D_{i, t, j^{\prime}, i^{\prime}, t}+\left(1-x_{i, t, j, i^{\prime}, t}\right) \cdot M_{2} & ; \quad \forall\left(i, t, j, i^{\prime}\right): i<i^{\prime}-1
\end{array}
$$

This condition can be satisfied by the constraint shown in Eq. (35) which imposes an upper bound on material transfer from a new slug $i$ to a depot $j$. Moreover, because of the liquid incompressibility, the overall volume transferred from the slugs in transit while pumping a new slug $i$ ' in period $t$ ' must be equal to $Q_{i}, t^{\prime}$, as shown in Eq. (36).

$$
\begin{aligned}
& F_{i+1, t, i^{\prime}-1, t^{\prime}} \leq \sigma_{j}-\sum_{j^{\prime}=1}^{j} D_{i, t, j^{\prime}, i^{\prime}, t^{\prime}}+\left(1-x_{i, t, j, i^{\prime}, t^{\prime}}\right) \cdot M_{2} \quad ; \quad \forall\left(i, t, j, i^{\prime}, t^{\prime}\right): i<I, i^{\prime}>1, t<t^{\prime} \\
& \sum_{i=1}^{i^{\prime}} \sum_{j=1}^{J} D_{i, t^{\prime}, j, i^{\prime}, t^{\prime}}+\sum_{i=1}^{I} \sum_{j=1}^{J} \sum_{t=1}^{t^{\prime}-1} D_{i, t, j, i^{\prime}, t^{\prime}}+\sum_{o=1}^{O} \sum_{j=1}^{J} D_{o, j, i^{\prime}, t^{\prime}}=Q_{i^{\prime}, t^{\prime}} \quad ; \quad \forall\left(i^{\prime}, t^{\prime}\right)
\end{aligned}
$$

The total volume transferred from a slug $s_{1}$ to all the depots other than the last depot while pumping a latter slug $s_{2}$ during the time interval $\left(C_{s 2}-L_{s 2}, C_{s 2}\right)$ should not exceed its saleable contents at time $C_{s 2-1}$. Whereas, the total volume transferred from slug $s_{1}$ to all depots including the last one must be less than its total volume (i. e. including the interface material) at time $C_{s 2-1}$. Thus, the interface will remain in the pipeline until reaching the last depot where it is withdrawn and reprocessed. Otherwise, a new interface will be generated, thus leading to higher product losses, Rejowski and Pinto (2001). The upper bound on material transfer from an old slug $o$ to all the depots other than the last depot is imposed by Eqs. (37), and that including the last depot by Eqs.(38). Similar sets of constraints were also formulated to impose upper bound on material transfer from new slugs $i$ to the depots by Eqs. (39) and (40).

$$
\begin{array}{ll}
\sum_{j=1}^{J-1} D o_{o, j, i, t} \leq W o_{o, i-1, t}-W I F 0_{o} & ; \quad \forall(o, i, t): i>1 \\
\sum_{j=1}^{J-1} D o_{o, j, 1, t} \leq W o_{o, I, t-1}-W I F 0_{o} & ; \quad \forall(o, t): t>1 \\
\sum_{j=1}^{J-1} D o_{o, j, 1,1} \leq W o_{o}-W I F 0_{o} & ; \quad \forall o
\end{array}
$$




$$
\begin{aligned}
& \sum_{j=1}^{J} D o_{o, j, i, t} \leq W o_{o, i-1, t, t} \quad ; \quad \forall(o, i, t): i>1 \\
& \sum_{j=1}^{J} D o_{o, j, 1, t} \leq W o_{o, I, t-1} \quad ; \quad \forall(o, t): t>1 \\
& \sum_{j=1}^{J} D o_{o, j, 1,1} \leq W 0_{o} \quad ; \quad \forall o \\
& \sum_{j=1}^{J-1} D_{i, t, j, i^{\prime}, t^{\prime}} \leq W_{i, t, i^{\prime}-1, t^{\prime}}-\sum_{p=1}^{P} \sum_{p^{\prime}=1}^{P} W I F_{i, t, p, p^{\prime}} \quad ; \quad \forall\left(i, t, i^{\prime}, t^{\prime}\right): i^{\prime}>1, t<t^{\prime} \\
& \sum_{j=1}^{J-1} D_{i, t, j, 1, t^{\prime}} \leq W_{i, t, I, t^{\prime}-1}-\sum_{p=1}^{P} \sum_{p^{\prime}=1}^{P} W I F_{i, t, p, p^{\prime}} \quad ; \quad \forall\left(i, t, t^{\prime}\right): t<t^{\prime} \\
& \sum_{j=1}^{J-1} D_{i, t, j, i^{\prime}, t} \leq W_{i, t, i^{\prime}-1, t}-\sum_{p=1}^{P} \sum_{p^{\prime}=1}^{P} W I F_{i, t, p, p^{\prime}} \quad ; \quad \forall\left(i, t, i^{\prime}\right): i<i^{\prime} \\
& \sum_{j=1}^{J-1} D_{i, t, j, i, t} \leq Q_{i, t}-\sum_{p=1}^{P} \sum_{p^{\prime}=1}^{P} W I F_{i, t, p, p^{\prime}} \quad ; \quad \forall(i, t) \\
& \sum_{j=1}^{J-1} D_{i, t, j, i^{\prime}, t^{\prime}} \leq W_{i, t, i^{\prime}-1, t^{\prime}} \quad ; \quad \forall\left(i, t, i^{\prime}, t^{\prime}\right): i^{\prime}>1, t<t^{\prime} \\
& \sum_{j=1}^{J-1} D_{i, t, j, 1, t^{\prime}} \leq W_{i, t, I, t^{\prime}-1} \quad ; \quad \forall\left(i, t, t^{\prime}\right): t<t^{\prime} \\
& \sum_{j=1}^{J-1} D_{i, t, j, j, i^{\prime}, t} \leq W_{i, t, i^{\prime}-1, t} \quad ; \quad \forall\left(i, t, i^{\prime}\right): i<i^{\prime} \\
& \sum_{j=1}^{J-1} D_{i, t, j, i, t} \leq Q_{i, t} \quad ; \quad \forall(i, t) \\
& \quad
\end{aligned}
$$

\subsection{Fulfillment of market demands}

There are also several constraints associated with the fulfillment of market demands. The constraints shown in Eqs. (41) state that the amount of product $p$ delivered from depot $j$ to local market during the time intervals $\left(C_{1, t}, h \max \cdot(t-1)\right),\left(C_{i, t}, C_{i}-1, t\right)$ and $\left(h \max \cdot t, C_{\Gamma}-1, t\right)$, must be supplied at the specified flow rate $v m$. Additionally, Eq. (42) states that the total volume of product $p$ transferred from depot $j$ to the local market during the time period $t$ should meet the overall demand $q d_{p, t, j}$.

$$
\begin{array}{ll}
q m_{p, j, 1, t} \leq\left(C_{1, t}-h \max \cdot(t-1)\right) \cdot v m & ; \quad \forall(t, p, j) \\
q m_{p, j, i, t} \leq\left(C_{i, t}-C_{i-1, t}\right) \cdot v m & ; \quad \forall(i, t, p, j): 1<i<I \\
q m_{p, j, I, t} \leq\left(h \max \cdot t-C_{I-1, t}\right) \cdot v m & ; \quad \forall(t, p, j) \\
\sum_{i=1}^{I} q m_{p, j, i, t}=q d_{p, j, t} \quad ; \quad \forall(t, p, j) &
\end{array}
$$

\subsection{Control of inventories in refinery tanks}

In order to control the inventory levels at refinery tanks it is necessary to define some binary variables: (a) a binary variable $z u_{i, t, r, p}$ with a value of 1 if the pumping of slug $i$ in period $t$ ends after beginning the loading of the $r^{\text {th }}$ production run of product $p$; and (b) a binary variable $z l_{i, t, r, p}$ with a value of 1 if the pumping of slug $i$ in period $t$ begun after completing the loading of the $r^{\text {th }}$ production run of product $p$. The values of these binary variables are fixed by the nonlinear constraints shown in Esq. (43) and (44). 
$\left(C R_{r, p, t}-L R_{r, p, t}\right) \cdot z u_{i, t, r, p} \leq C_{i, t} \leq C R_{r, p, t}-L R_{r, p, t}+h \max \cdot t \cdot z u_{i, t, r, p} \quad ; \quad \forall(i, t, r, p)$

$C R_{r, p, t} \cdot z l_{i, t, r, p} \leq C_{i, t}-L_{i, t} \leq C R_{r, p, t}+$ hmax $\cdot t \cdot z l_{i, t, r, p} \quad ; \quad \forall(i, t, r, p)$

- Volume of production run $r$ of product p already loaded in the assigned refinery tank at time Ci,t.

The variable $q u_{i, t, r, p}$ is the volume of $r^{\text {th }}$ production run of product $p$ in period $t$ already loaded in the designated refinery tank at time $C_{i, t}$. Three cases can be considered:

(a) $C_{i, t} \geq C R_{r, p, t}$, then $z u_{i, t, r, p}=1$ and the full run $r$ has been loaded in the designated tank

(b) $C_{i, t} \leq C R_{r, p, t}-L R_{r, p, t}$, then $z l_{i, t, r, p}=0$ and the production run $r$ has not yet begun

(c) $C R_{r, p, t}-L R_{r, p, t} \leq C_{i, t} \leq C R_{r, p, t}$ then $z l_{i, t, r, p}=1$ and a portion of the production run $r$ has been loaded in the designated tank the time interval of $\left(C R_{r, p, t}-L R_{r, p, t}, C_{i, t}\right)$

Considering the above three cases, an upper bound on $q u_{i, t, r, p}$ can be set by the following nonlinear constraints:

$$
\begin{aligned}
& q u_{i, t, r, p} \leq v r_{p} \cdot L R_{r, p, t} \cdot z u_{i, t, r, p} \quad ; \quad \forall(i, t, r, p) \\
& q u_{i, t, r, p} \leq v r_{p} \cdot\left[C_{i, t}-\left(C R_{r, p, t}-L R_{r, p, t}\right) \cdot z u_{i, t, r, p}\right] ; \quad \forall(i, t, r, p)
\end{aligned}
$$

The variable $q l_{i, t, r, p}$ is volume of $r^{\text {th }}$ production run of product $p$ in period $t$ already loaded in the designated refinery tank at time $C_{i, t}-L_{i, t}$. Two cases can be considered:

(a) $\left(C_{i, t}-L_{i, t}\right) \geq C R_{r, p, t}$, then $q l_{i, t, r, p}=1$ and the full run $r$ has been loaded in the designated tank at time $\left(C_{i, t}-L_{i, t}\right)$

(b) $\left(C_{i, t}-L_{i, t}\right) \leq C R_{r, p, t}$, then $q l_{i, t, r, p}=0$ and a portion of the production run $r$ has been loaded in the designated tank at time $\left(C_{i, t}-L_{i, t}\right)$

Considering the above three cases, a lower bound on $q l_{i, t, r, p}$ can be set by the nonlinear constraints shown in Eqs. (47) and (48), where $M_{3}=1.1 \times \max \left(v r_{p}\right) \times h \max$.

$$
\begin{aligned}
& q l_{i, t, r, p} \geq v r_{p} \cdot L R_{r, p, t} \cdot z l_{i, t, r, p} \quad ; \quad \forall(i, t, r, p) \\
& q l_{i, t, r, p} \geq v r_{p} \cdot\left[\left(C_{i, t}-L_{i, t}\right)-\left(C R_{r, p, t}-L R_{r, p, t}\right)\right]-M_{3} \cdot z l_{i, t, r, p} \quad ; \quad \forall(i, t, r, p)
\end{aligned}
$$

- Volume of product $p$ withdrawn from refinery tank and pumped in the pipeline during the time interval of $\left(C_{i, t}-L_{i, t}, C_{i, t}\right)$.

The volume of the material withdrawn from the refinery tank containing product $p$ and pumped as the $i^{\text {th }}$ slug in period $t$ is equal to the volume of the slug $Q_{i, t}$ if the slug has been assigned to product $p$ (i.e. $\left.y_{i, t, p}=1\right)$. Otherwise, no material is withdrawn from the refinery tank during the time interval of $\left(C_{i, t}-L_{i, t}, C_{i, t}\right)$.

$$
\begin{aligned}
& A_{i, t, p} \leq M_{2} \cdot y_{i, t, p} \quad ; \quad \forall(i, t, p) \\
& \sum_{p=1}^{P} A_{i, t, p}=Q_{i, t} \quad ; \quad \forall(i, t)
\end{aligned}
$$


- Maximum and minimum allowed inventories in refinery tanks.

The inventory level at a refinery tank must be greater than the minimum allowable level $\operatorname{IRmin}_{p}$ at the end of every pumping run as shown in Eqs. (51), and less than the maximum allowable level $\operatorname{IRmin}_{p}$ at the start of every pumping run shown in Eqs. (52).

$$
\begin{aligned}
& I R F_{p, i, 1}=I R O_{p}+\sum_{r=1}^{R} q u_{i, 1, r, p}-\sum_{i^{\prime}=1}^{i} A_{i^{\prime}, 1, p} \geq I \operatorname{Imin}_{p} \quad ; \quad \forall(i, p) \\
& I R F_{p, i, t}=I R F_{p, I, t-1}+\sum_{r=1}^{R} q u_{i, t, r, p}-\sum_{i^{\prime}=1}^{i} A_{i^{\prime}, t, p} \geq I R \operatorname{Imin}_{p} \quad ; \quad \forall(i, t, p): t>1 \\
& I R S_{p, i, 1}=I R 0_{p}+\sum_{r=1}^{R} q l_{i, 1, r, p}-\sum_{i^{\prime}=1}^{i} A_{i^{\prime}, 1, p} \geq I \operatorname{Imax}_{p} \quad ; \quad \forall(i, p) \\
& I R S_{p, i, t}=I R S_{p, I, t-1}+\sum_{r=1}^{R} q l_{i, t, r, p}-\sum_{i^{\prime}=1}^{i} A_{i^{\prime}, t, p} \geq I \operatorname{IRmax}_{p} \quad ; \quad \forall(i, t, p): t>1
\end{aligned}
$$

\subsection{Control of inventories in depot tanks}

Finally, the amount of product $p$ transferred from a slug to a depot while pumping another slug is calculated using the constraints shown in Eqs. (53)-(56). Moreover, Eq. (57) and Eq. (58) are used to keep all the inventory levels into its feasible ranges.

$$
\begin{aligned}
& D V o_{o, p, j, i, t} \leq M_{2} \cdot y o_{o, p} \quad ; \quad \forall(o, p, j, i, t) \\
& \sum_{p=1}^{P} D V o_{o, p, j, i, t}=D_{o, j, i, t} \quad ; \quad \forall(o, j, i, t) \\
& D V_{i, t, p, j, i^{\prime}, t^{\prime}} \leq M_{2} \cdot y_{i, t, p} \quad ; \quad \forall\left(i, t, p, j, i^{\prime}, t^{\prime}\right): t<t^{\prime} \\
& D V_{i, t, p, j, i^{\prime}, t} \leq M_{2} \cdot y_{i, t, p} \quad ; \quad \forall\left(i, t, p, j, i^{\prime}\right): i \leq i^{\prime} \\
& \sum_{p=1}^{P} D V_{i, t, p, j, i^{\prime}, t^{\prime}}=D_{i, t, j, i^{\prime}, t^{\prime}} \quad ; \quad \forall\left(i, t, p, i^{\prime}, t^{\prime}\right): t<t^{\prime} \\
& \sum_{p=1}^{P} D V_{i, t, p, j, i^{\prime}, t}=D_{i, t, j, i^{\prime}, t} \quad ; \quad \forall\left(i, t, p, i^{\prime}\right): i \leq i^{\prime} \\
& \operatorname{IDmin}_{p, j} \leq I D_{p, j, i, t} \leq \operatorname{IDmax}_{p, j} \quad ; \quad \forall(p, j, i, t) \\
& I D_{p, j, i^{\prime}, t^{\prime}}=I D_{p, j, i^{\prime}-1, t^{\prime}}+\left(\sum_{i=1}^{i^{\prime}} D V_{i, t^{\prime}, p, j, i^{\prime}, t^{\prime}}+\sum_{i=1}^{I} \sum_{t=1}^{t^{\prime}-1} D V_{i, t, p, j, i^{\prime}, t^{\prime}}+\sum_{o=1}^{O} D V o_{o, p, j, i^{\prime}, t^{\prime}}\right)-q m_{p, j, i^{\prime}, t^{\prime}} \quad ; \forall\left(p, j, i^{\prime}, t^{\prime}\right): i^{\prime}>1 \\
& I D_{p, j, 1, t^{\prime}}=I D_{p, j, I, t^{\prime}-1}+\left(D V_{1, t^{\prime}, p, j, 1, t^{\prime}}+\sum_{i=1}^{I} \sum_{t=1}^{t^{\prime}-1} D V_{i, t, p, j, 1, t^{\prime}}+\sum_{o=1}^{O} D V o_{o, p, j, 1, t^{\prime}}\right)-q m_{p, j, i, t^{\prime},} \quad ; \forall\left(p, j, t^{\prime}\right): t^{\prime}>1 \\
& I D_{p, j, 1,1}=I D 0_{p, j}+\left(D V_{1,1, p, j, 1,1}+\sum_{o=1}^{O} D V o_{o, p, j, 1,1}\right)-q m_{p, j, 1,1} \quad ; \forall(p, j)
\end{aligned}
$$

\section{Numerical Examples}

The proposed MINLP model will be illustrated by solving a large-scale product pipeline scheduling problem involving two periods under several scenarios. The first scenario is to illustrate the possibility of an infeasible solution in the second period where a single period model is used independently for two periods. The second scenario illustrates the cost saving in using a multi-period model even when feasible solutions can be obtained by solving a single-period model for the two periods, independently. The last scenario is to illustrate the advantage of integrating the production planning and scheduling with the transportation. Data for the first period in all the scenarios were taken for the example first introduced by Rejowski and Pinto (2003) and next by Cafaro and Cerdá (2004). Data for the second period were chosen to prove, through the three scenarios, the proposed multi-period model reduces the total cost compared with the single-period one. All the scenarios 
involve a single pipeline transporting four refined petroleum products (P1: Gasoline; P2: Diesel oil; P3: LPG; P4: Jet fuel) to five distribution terminals (D1-D5) located along the pipeline. The locations of the five depots with regards to the pipeline origin are 100,200, 300, 400 and 475, respectively in hundred of cubic meters. Common data for all the scenarios are shown in Tables 1 and 2. Table 1 shows the minimum, the maximum and the initial inventory levels for all the products at the refinery and all depots together with the inventory and the pumping costs. The interface material cost and volume for each ordered pair of products are given in Table 2. In this table, there are two forbidden product sequences $(\mathrm{P} 1-\mathrm{P} 3)$ and $(\mathrm{P} 3-\mathrm{P} 4)$, denoted with $\mathrm{a} \times$ symbol. Other parameters of the model are Imin $=1 \mathrm{~h}, \operatorname{lmax}=h \max =75 \mathrm{~h}, \rho=5000 \mathrm{US} \$ / \mathrm{m}^{3}, v b \min$ and $v b \max$ are equal to $v m=500 \mathrm{~m}^{3} / \mathrm{h}$ and $\tau=0 \mathrm{~s}$.

Table 1

Levels, inventory cost and pumping cost

\begin{tabular}{llllllll}
\hline Product & Characteristic & Refinery & \multicolumn{5}{c}{ Depots } \\
\cline { 5 - 7 } & & & $\mathrm{D} 1$ & $\mathrm{D} 2$ & $\mathrm{D} 3$ & $\mathrm{D} 4$ & $\mathrm{D} 5$ \\
\hline P1 & Minimum level $\left(\times 10^{2} \mathrm{~m}^{3}\right)$ & 270 & 90 & 90 & 90 & 90 & 90 \\
& Maximum level $\left(\times 10^{2} \mathrm{~m}^{3}\right)$ & 1200 & 400 & 400 & 400 & 400 & 400 \\
& Initial level $\left(\times 10^{2} \mathrm{~m}^{3}\right)$ & 500 & 190 & 230 & 200 & 240 & 190 \\
& Inventory cost $\left(\mathrm{US} \$\left(\mathrm{~m}^{3} \mathrm{~h}\right)\right)$ & 0.070 & 0.100 & 0.100 & 0.100 & 0.100 & 0.100 \\
& Pumping cost $\left(\mathrm{US} \$ / \mathrm{m}^{3}\right)$ & $\times$ & 3.5 & 4.5 & 5.5 & 6.0 & 6.9 \\
\hline P2 & Minimum level $\left(\times 10^{2} \mathrm{~m}^{3}\right)$ & 270 & 90 & 90 & 90 & 90 & 90 \\
& Maximum level $\left(\times 10^{2} \mathrm{~m}^{3}\right)$ & 1200 & 400 & 400 & 400 & 400 & 400 \\
& Initial level $\left(\times 10^{2} \mathrm{~m}^{3}\right)$ & 520 & 180 & 210 & 180 & 180 & 180 \\
& Inventory cost $\left(\mathrm{US} \$\left(\mathrm{~m}^{3} \mathrm{~h}\right)\right)$ & 0.080 & 0.155 & 0.155 & 0.155 & 0.155 & 0.155 \\
& Pumping cost $\left(\mathrm{US} \$ / \mathrm{m}^{3}\right)$ & $\times$ & 3.6 & 4.6 & 5.6 & 6.2 & 7.3 \\
\hline P3 & Minimum level $\left(\times 10^{2} \mathrm{~m}^{3}\right)$ & 50 & 10 & 10 & 10 & 10 & 10 \\
& Maximum level $\left(\times 10^{2} \mathrm{~m}^{3}\right)$ & 350 & 70 & 70 & 70 & 70 & 70 \\
& Initial level $\left(\times 10^{2} \mathrm{~m}^{3}\right)$ & 210 & 50 & 65 & 60 & 60 & 60 \\
& Inventory cost $\left(\mathrm{US} \$ /\left(\mathrm{m}^{3} \mathrm{~h}\right)\right)$ & 0.095 & 0.200 & 0.200 & 0.200 & 0.200 & 0.200 \\
& Pumping cost $\left(\mathrm{US} \$ / \mathrm{m}^{3}\right)$ & $\times$ & 4.8 & 5.7 & 6.8 & 7.9 & 8.9 \\
\hline P4 & Minimum level $\left(\times 10^{2} \mathrm{~m}^{3}\right)$ & 270 & 90 & 90 & 90 & 90 & 90 \\
& Maximum level $\left(\times 10^{2} \mathrm{~m}^{3}\right)$ & 1200 & 400 & 400 & 400 & 400 & 400 \\
& Initial level $\left(\times 10^{2} \mathrm{~m}^{3}\right)$ & 515 & 120 & 140 & 190 & 190 & 170 \\
& Inventory cost $\left(\mathrm{US} \$ /\left(\mathrm{m}^{3} \mathrm{~h}\right)\right)$ & 0.090 & 0.170 & 0.170 & 0.170 & 0.170 & 0.170 \\
& Pumping cost $\left(\mathrm{US} \$ / \mathrm{m}^{3}\right)$ & $\times$ & 3.7 & 4.7 & 5.7 & 6.1 & 7.0
\end{tabular}

The cardinality of the set $I$, i.e. the number of new pumping runs, is initially assumed to be equal to the number of oil derivatives transported by the pipeline. After solving the model, the cardinality of $I$ is increased by one and the model is solved again.

Table 2

Interface material volumes and cost

\begin{tabular}{|c|c|c|c|c|c|c|c|c|}
\hline & \multicolumn{4}{|c|}{ Interface volume $\left(\mathrm{m}^{3}\right)$} & \multicolumn{4}{|c|}{ Interface cost $\left(\mathrm{US} \$ / \mathrm{m}^{3}\right)$} \\
\hline & $\mathrm{P} 1$ & $\mathrm{P} 2$ & $\mathrm{P} 3$ & $\mathrm{P} 4$ & $\mathrm{P} 1$ & $\mathrm{P} 2$ & $\mathrm{P} 3$ & $\mathrm{P} 4$ \\
\hline $\mathrm{P} 1$ & 0 & 30 & 37 & 35 & 0 & 100 & 100 & 100 \\
\hline $\mathrm{P} 2$ & 30 & 0 & $x$ & 38 & 100 & 0 & $x$ & 100 \\
\hline P3 & 35 & $x$ & 0 & $x$ & 100 & $x$ & 0 & $x$ \\
\hline P4 & 37 & 38 & $x$ & 0 & 100 & 100 & $x$ & 0 \\
\hline
\end{tabular}


The procedure is repeated until no further decrease in the pipeline operation cost at the optimum is achieved. In all the scenarios, the optimal solution was found at the first major iteration. After linearizing the MINLP model according to the process shown in the Appendix I and adding the speed-up constraints shown in Appendix II, the resulting MILP mathematical formulation was solved on a Pentium IV 2.6 GHz / 512 MB RAM processor with CPLEX using ILOG OPL Studio 3.6, ILOG (2003).

\subsection{Scenario I: Feasible solutions for several periods}

The first example involves two periods of $75 \mathrm{~h}$ each. A pair of time intervals for each period $(15 \mathrm{~h}-25 \mathrm{~h}$ and $40 \mathrm{~h}-50 \mathrm{~h}$ for the first period; $90 \mathrm{~h}-100 \mathrm{~h}$ and $115 \mathrm{~h}-125 \mathrm{~h}$ for the second one) presents much higher pumping cost. Usually, the pipeline stream is stopped during high-energy cost intervals, unless unsatisfied products demands force to keep the slug sequence moving along the pipeline. Data for this scenario are given in Tables 3 and 4 . Table 3 provides the product demands to be satisfied at each distribution terminal at the end of each period. Table 4 shows the scheduled production runs at the oil refinery for both periods. There is initially a sequence of five old slugs (S5-S4-S3-S2-S1) inside the pipeline containing products (P1-P2-P1-P2-P1) arranged in this order, and featuring the following volumes $(75 / 175 / 125 / 25 / 75)$ in hundred of cubic meters. Slug S1 occupies the farthest position from the refinery plant.

Table 3

Product demands for each period

\begin{tabular}{|c|c|c|c|c|c|c|c|c|c|c|}
\hline & \multicolumn{5}{|c|}{ Demand for period $1\left(\times 10^{2} \mathrm{~m}^{3}\right)$} & \multicolumn{5}{|c|}{ Demand for period $2\left(\times 10^{2} \mathrm{~m}^{3}\right)$} \\
\hline & D1 & D2 & D3 & D4 & D5 & D1 & D2 & D3 & D4 & D5 \\
\hline $\mathrm{P} 1$ & 100 & 110 & 120 & 120 & 150 & 20 & 20 & 20 & 20 & 20 \\
\hline P2 & 70 & 90 & 100 & 80 & 100 & 20 & 20 & 20 & 20 & 20 \\
\hline P3 & 60 & 40 & 40 & 0 & 20 & 20 & 20 & 20 & 20 & 20 \\
\hline P4 & 60 & 50 & 50 & 50 & 50 & 20 & 20 & 20 & 20 & 40 \\
\hline
\end{tabular}

\section{Table 4}

Scheduled production runs at the oil refinery for each period

\begin{tabular}{|c|c|c|c|c|c|c|c|}
\hline \multicolumn{4}{|c|}{ Data for period 1} & \multicolumn{4}{|c|}{ Data for period 2} \\
\hline Product & $\begin{array}{l}\text { Volume } \\
\left(\times 10^{2} \mathrm{~m}^{3}\right)\end{array}$ & $\begin{array}{l}\text { Rate } \\
\left(\times 10^{2} \mathrm{~m}^{3} / \mathrm{h}\right)\end{array}$ & Interval (h) & Product & $\begin{array}{l}\text { Volume } \\
\left(\times 10^{2} \mathrm{~m}^{3}\right)\end{array}$ & $\begin{array}{l}\text { Rate } \\
\left(\times 10^{2} \mathrm{~m}^{3} / \mathrm{h}\right)\end{array}$ & Interval (h) \\
\hline $\mathrm{P} 1$ & 250 & 5 & $0-50$ & $\mathrm{P} 1$ & 250 & 5 & $75-125$ \\
\hline $\mathrm{P} 2$ & 250 & 5 & $0-50$ & $\mathrm{P} 2$ & 250 & 5 & $75-125$ \\
\hline P3 & 125 & 5 & $50-75$ & P3 & 125 & 5 & $125-150$ \\
\hline $\mathrm{P} 4$ & 125 & 5 & $50-75$ & $\mathrm{P} 4$ & 125 & 5 & $125-150$ \\
\hline
\end{tabular}

Firstly, the problem is solved for the first period and the results are compared with the proposed ones in Cafaro and Cerdá (2004) where the data for this period was taken from. Since we use different term in the objective function to calculate the inventory cost at refinery, some differences are expected. Fig.2a shows the optimal solution when only the pumping sequence for the first period is optimized. The optimal pipeline operation cost is 3,310,333 US\$. The model involves 2193 constraints and 1540 variables. The solution was found after 22 seconds of computation. This solution is compared in Fig.2b with the reported one by Cafaro and Cerdá (2004) where the cost operation is $3,274,683$ US\$. Both solutions are quite similar with a small difference due to the different term used in the objective function to calculate the inventory cost at refinery. Variations of product inventory at refinery and all depot tanks over time can be calculated through simulation. 
Fig.2c shows such variations for the solution shown in Fig.2a. As can be seen, all inventory levels remain in their permissible ranges. Moreover, product inventories at depot tanks tend to remain close to their minimum values over the planning horizon because of their higher inventory costs. As it was stated on section 2.1, the term used in the objective function to calculate the inventory cost at refinery and depots is an approximation of the real value, based on an average value of each product inventory over the time horizon. Hence, after the optimization is completed, it is possible to calculate the real inventory cost and compare it with the estimated one by the model in order to evaluate the goodness of such approximation. The results of this calculation are given in Table 5. As can be seen from this table, the difference between the real value and the estimated one by the approximation used on the objective function is less than $6 \%$ in all cases. Hence, the use of such linear approximation to calculate the inventory cost instead of a non-linear term that calculates it exactly is completely justified.

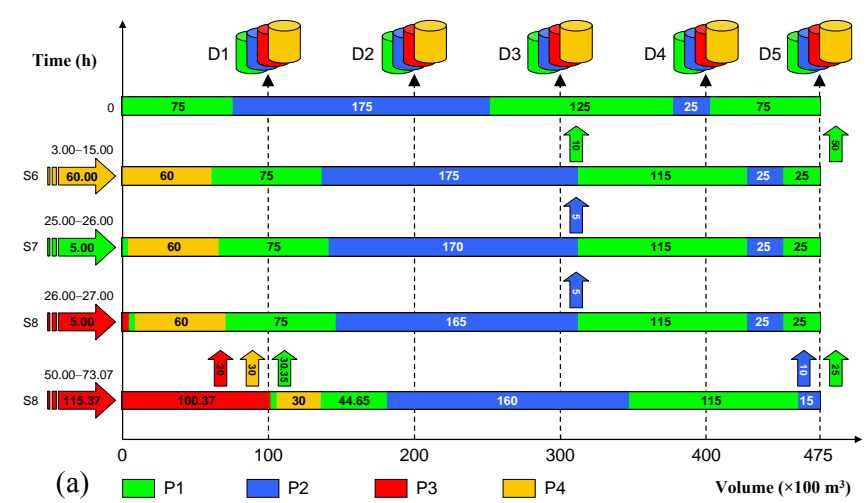

(a) Proposed model

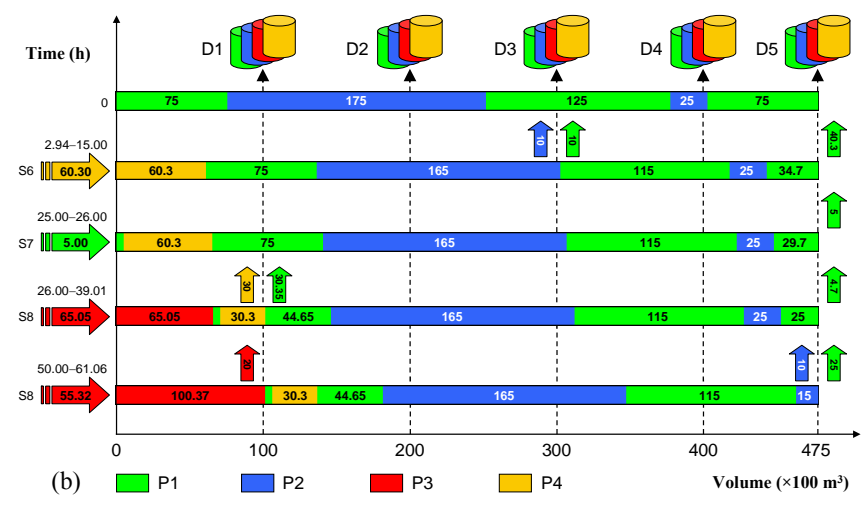

(b) Cafaro and Cerdá 2004
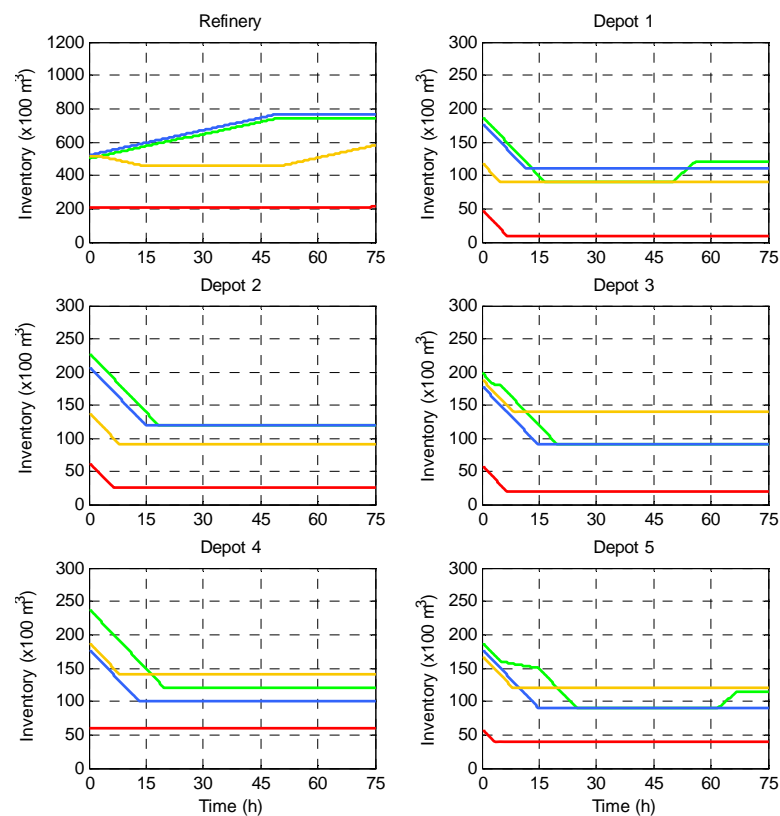

(c)Evolution of inventories at refinery and depot tanks for the solution shown in Fig 2a

Fig. 2. Optimal pipeline schedule for the first period in Scenario I

Table 5

Comparison between the real and the calculated inventory levels

\begin{tabular}{lllllll}
\hline & Refinery & \multicolumn{2}{l}{ Depots } & & & \\
\cline { 3 - 7 } & & D1 & D2 & D3 & D4 & D5 \\
\hline Model (US\$) & $1,212,272.32$ & $332,694.37$ & $385,500.00$ & $386,250.00$ & $480,375.00$ & $401,062.50$ \\
Real (US\$) & $1,234,375.90$ & $350,052.97$ & $408,571.82$ & $409,049.72$ & $498,760.83$ & $416,192.68$ \\
Difference (\%) & $1.79 \%$ & $4.96 \%$ & $5.65 \%$ & $5.57 \%$ & $3.69 \%$ & $3.64 \%$ \\
\hline
\end{tabular}


According to Fig.2a, it can be seen how the pipeline remains operative from time $3 \mathrm{~h}$ to $73.07 \mathrm{~h}$ with two temporary stops including the high-energy cost periods going from $15 \mathrm{~h}$ to $25 \mathrm{~h}$ and from $27 \mathrm{~h}$ to $50 \mathrm{~h}$. In other words, it will be working a total of $48.93 \mathrm{~h}$ well below the overall length of the scheduling horizon (75h). Therefore, the pipeline capacity largely exceeds the customer demands to be satisfied by pumping new product slugs into the pipeline. Only three new slugs (S8-S7-S6) containing products (P3-P1-P4) in the following volumetric quantities (120.35/5.0/60), expressed in hundred cubic meters, are pumped into the pipeline over the time horizon. If some demand is specified for the second period, it could happen that no feasible solution can be reached for that period by running the single-period model from the final state let by the first period. Then, all the time that the pipeline remains inoperative could have been used to pump additional material useful to satisfy the demand for the second period from the product inventory at depot tanks. The only way to take it into account is by running a multi-period model which is capable to deal with the information concerning both periods together in the same model.

To illustrate this situation, the single-period model is run from the final state let at the end of the first period. Such state is composed by a sequence of seven old slugs (S7-S6-S5-S4-S3-S2-S1) inside the pipeline containing products (P3-P1-P4-P1-P2-P1-P2) arranged in this order, and featuring the following volumes $(100.37 / 5 / 0.35 / 74.28 / 165 / 115)$ in hundreds of cubic meters. Slug S1 occupies the farthest position from the refinery plant. When using this initial state together with the information given in Tables 3 and 4 to obtain the optimal pipeline schedule for the second period, the single-period model is unable to reach any feasible solution. The reason is because the model is unable to pump the necessary amount of product 4 to depot 5 before the end of the planning horizon. This situation could have been avoided if such amount of P4 had been pumped during the time in which the pipeline was inoperative at the first period. However, the single-period model is unable to find this solution since both periods are run, independently. Fig.3 shows the optimal solution when the multi-period model is run.
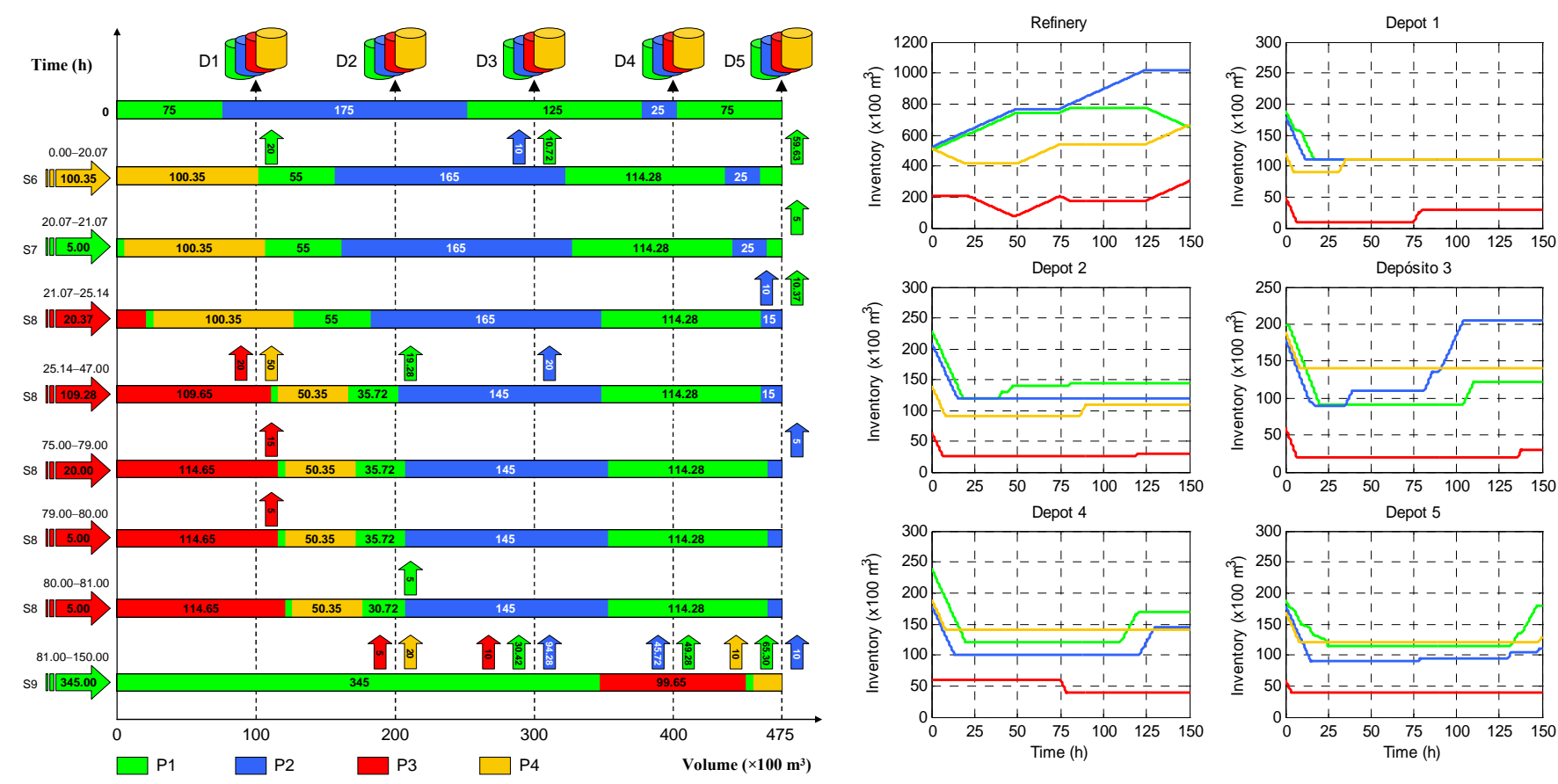

Fig. 3. Optimal pipeline schedule reached by the multi-period model for both periods in Scenario I

As can be seen, this model is able to reach a feasible and optimal solution since data for both periods are taken into account into the same optimization process, simultaneously. In this case, the model involves 8428 constraints and 5020 variables. The optimal solution is found after 4885 seconds of computation and has a pipeline operation cost of $6,596,453$ US\$. The solution is composed by 5 
slugs, however the model uses 8 (4 in each period). This allows a more precise calculation of the inventory cost on the objective function. Additional material of product 1 was pumped on the last new slug and a portion of the high-energy cost intervals are used to pump product into the pipeline. This portion is $37 \mathrm{~h}$ of the total of $40 \mathrm{~h}$ that comprises the high-energy cost intervals. Then, a $92.5 \%$ of the high-energy cost intervals is used to pump material into the pipeline. This is needed to push 10 units of product 4 on the first new slug to depot 5. Usually, the planning horizon is divided into a number of equal-length periods, and demands must be fulfilled when these periods end. At the completion time of the current period, the planning horizon moves forward, and a rescheduling process based on updated problem data is triggered again over the new horizon. In our case, we have a planning horizon composed by two periods of 75 hour each. Hence, we have 75 hours to solve the problem before the planning horizon moves one period forward to update the problem data. As we can see, this is enough time since an off-shelf optimization package is able to solve the two-period problem on this scenario in less than two hours. However, we also realized that if we tried to solve the proposed multi-period model for three or more time periods using off-shelf optimization package, it could be very time consuming. On these cases, it could be necessary to develop a heuristic algorithm to reach near-optimal solutions into the available time given by the period length.

\subsection{Scenario II: Improvement of a feasible solution for several periods}

The second scenario involves the same periods treated on scenario 1 . However, the demand for the second period is chosen to show how even in the case when a feasible solution can be reached by the single-period model for both periods, the multi-period model improves the quality of such solution. Hence, data for this scenario is the same as given on Tables 3 and 4 but replacing the $40 \times 10^{2} \mathrm{~m}^{3}$ of P4 demanded by D5 at period 2 by $20 \times 10^{2} \mathrm{~m}^{3}$. With this change, the single-period model is able to reach a feasible and optimal solution for both periods, independently. The optimal solution for the first period was shown in Fig.2a with an optimal pipeline operation cost of 3,310,333 US\$. Now, the single-period model is used again to get the optimal solution for period 2 from the final state in period 1 shown in Fig.2a. The optimal solution for period 2 was found after 28 seconds of computation with a pipeline operation cost of 3,385,957 US\$. Hence, the total computation time was $43.23 \mathrm{~s}$. The total operation cost for both periods is the sum of the costs obtained for each period, resulting in 6,696,291 US\$. Fig. 4 shows the optimal pipeline schedule reached by the single-period model over both periods. Variations of product inventories at refinery and depot tanks with time are also depicted. Note that inventory levels remain within the accepteble range at every tank.

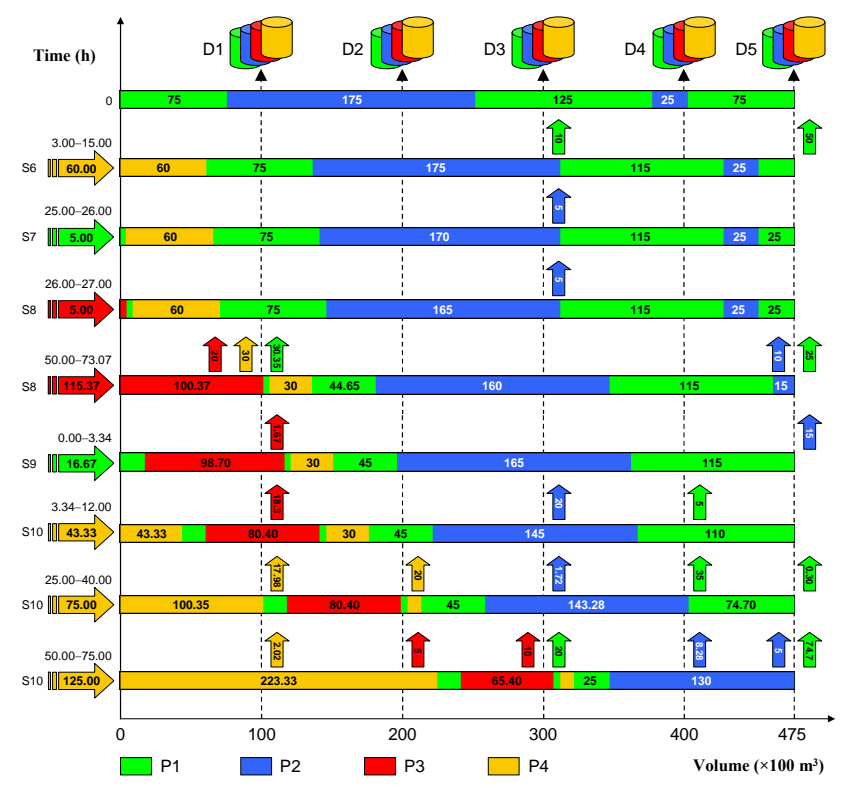

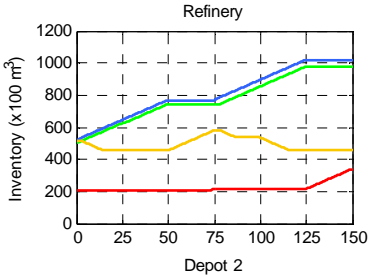
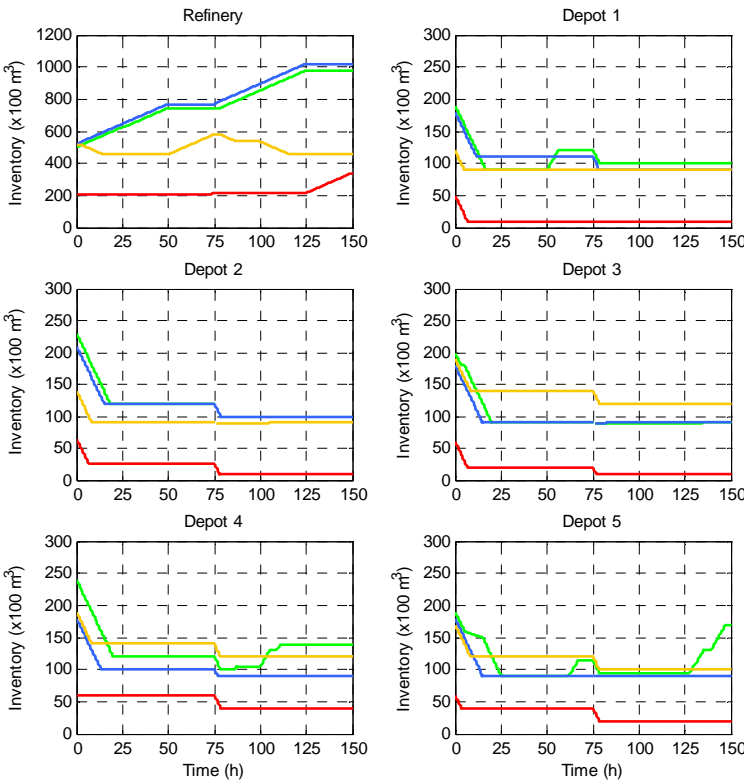

Fig. 4. Optimal pipeline schedule reached by the single-period model for both periods in Scenario II 
Now, the same problem is solved with the proposed multi-period model for both periods, simultaneously. In this case the model involves 8428 constraints and 5020 variables. The optimal solution was found after 4948 seconds of computation with a pipeline operation cost of $6,437,027$ US\$. It results in a cost saving of 259,264 US\$ from the solution given by the single-period model. The optimal pipeline schedule reached in this scenario is depicted in Fig.5 together with the variations of product inventories at refinery and depot tanks over both periods. As it can be seen, the solution is composed by 6 slugs. Some portion of the high-energy cost intervals are used to pump product in benefit of the inventory cost. This portion is $25.07 \mathrm{~h}$ of the total of $40 \mathrm{~h}$ that comprises the high-energy cost intervals. Then, a $62.67 \%$ of the high-energy cost intervals is used to pump material into the pipeline. Table 6 summarizes a comparison between both single and multi-period models for scenario II. As can be seen, although the multi-period model improves the quality of the solution reached by the single-period model, the computational time is increased two orders of magnitude. The improvement on the quality of solution depends on the problem data. In the proposed example it is only of $4 \%$, however, it is a great savings taking into account the high cost involved on such a kind of processes.
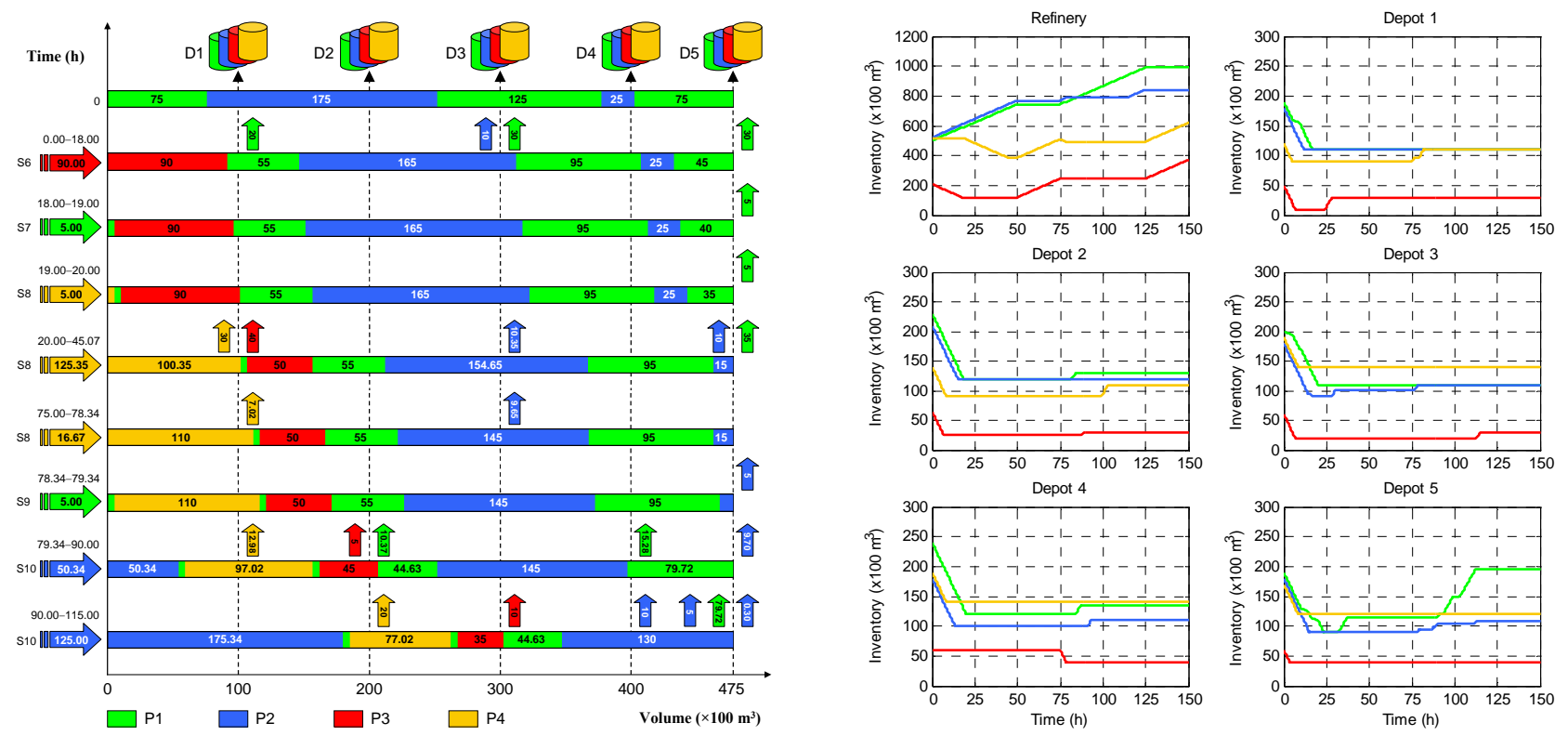

Fig. 5. Optimal pipeline schedule reached by the multi-period model for both periods in Scenario II

Table 6

Comparison between the single-period (SP) and multi-period model (MP)

\begin{tabular}{|c|c|c|c|c|c|}
\hline \multirow{2}{*}{ Model } & \multicolumn{2}{|c|}{ Variables } & \multirow{2}{*}{ Constraints } & \multirow{2}{*}{ CPU time (s) } & \multirow{2}{*}{ Cost (US\$) } \\
\hline & Binary & Continuous & & & \\
\hline SP (Period 1) & 244 & 1296 & 2193 & 22 & $3,310,333$ \\
\hline SP (Period 2) & 244 & 1296 & 2193 & 28 & $3,385,957$ \\
\hline SP (Total) & 244 & 1296 & 2193 & 50 & $6,696,291$ \\
\hline MP & 858 & 4162 & 8428 & 4948 & $6,437,027$ \\
\hline
\end{tabular}

\subsection{Scenario III: Integrating the production planning as a decision variable}

In this scenario, production planning and scheduling was considered to be part of the decision making process and the multi-period model was solved to generate the planning and scheduling of both the production and the transportation. In this case the model involves 8564 constraints and 5116 variables. The optimal solution was found after 5125 seconds of computation with a pipeline operation cost of 5,874,750 US\$. The optimal pipeline schedule reached in this scenario is depicted in 
Fig. 6 together with the variations of product inventories at refinery and depot tanks over both periods. As it can be seen, the solution is composed by 5 slugs. The integration of production and transportation results in a reduction of the pumping cost during high electric energy interval from 125,370 to 30,720 dollars as it is shown on Table 7 . This is due to a reduction on the usage of the peak-hour intervals from $62.67 \%$ in the Scenario II to $15.36 \%$ in Scenario III. The saving was archived by synchronizing the production with the transportation. This synchronization enables avoiding the need for pumping during high electric energy intervals which otherwise would be required to provide rooms in the refinery tanks for the newly refined products.
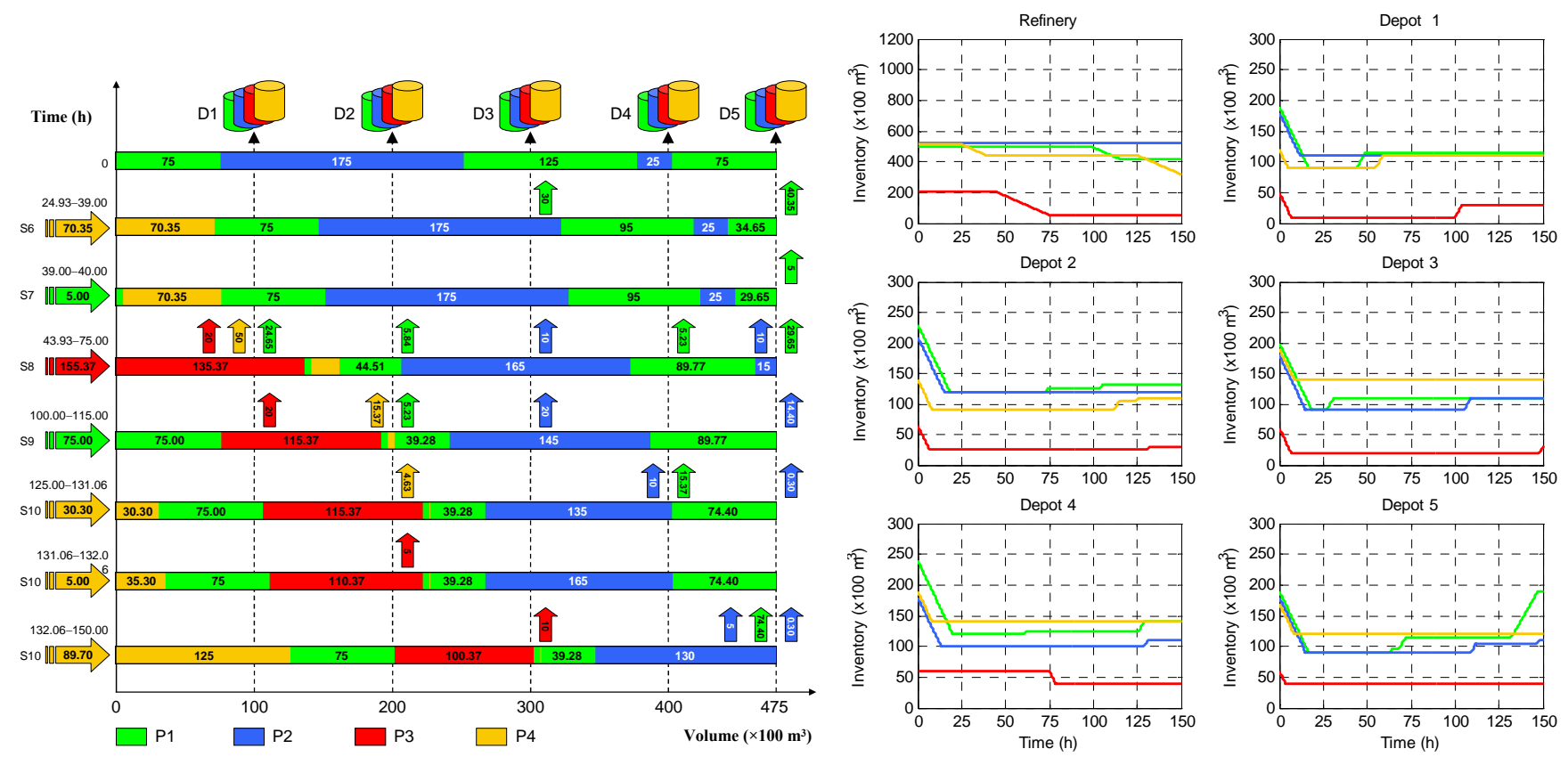

Fig. 6. Optimal pipeline schedule reached by the multi-period model with production planning for both periods in Scenario III

Table 7

Cost (US\$) associated to each term of the objective function for all the models at scenario III

\begin{tabular}{lllllll}
\hline & $\begin{array}{l}\text { Daily normal } \\
\text { Model }\end{array}$ & $\begin{array}{l}\text { Peak hours } \\
\text { pumping cost }\end{array}$ & $\begin{array}{l}\text { Interface } \\
\text { pumping cost }\end{array}$ & $\begin{array}{l}\text { Inventory cost } \\
\text { at depots }\end{array}$ & $\begin{array}{l}\text { Inventory cost } \\
\text { at refinery }\end{array}$ & TOTAL \\
\hline SP & 256,279 & 0 & 17,900 & $3,712,701$ & $2,709,410$ & $6,696,291$ \\
MP & 245,741 & 125,370 & 17,400 & $3,725,074$ & $2,323,442$ & $6,437,027$ \\
MP+PP & 247,205 & 30,720 & 17,900 & $3,725,203$ & $1,853,722$ & $\mathbf{5 , 8 7 4 , 7 5 0}$ \\
\hline
\end{tabular}

\section{Conclusions}

In this paper we have proposed a multi-period MINLP model for an optimal planning and scheduling of the production and transportation of multiple petroleum products from a refinery plant connected to several depots through a single pipeline system. Numerical examples show that the use of a single period model for a given time period may lead to an infeasible solution when using the model for the upcoming periods. The reason is because the demand in the upcoming periods are not considered in the optimization process, the minimization of the objective function will satisfy the current demands from inventories in depots to reduce inventory cost. This will cause the inventories in the depots to fall to the minimum level. Thus, when using the model for the upcoming periods the solution may be infeasible to satisfy the demands due to the delay of delivery through the pipeline. The numerical examples also show that integrating production transportation decisions can result in reduced pipeline operational costs. The size of the developed model will be quite large if applied to solve practical 
problems. The model also contains a significant portion of binary integer variables. The presence of integer variables in the model may lead to extensive computational time in solving real world problems. In Scenario II of the numerical example presented in this paper, the computational time required to solve the multi-period model for two time periods was more than 100 times than the time required to solve a single-period model twice. We also realized that solving the proposed multi-period model for three or more time periods using off-shelf optimization package is very time consuming. To this end, we are currently working on a heuristic method based on genetic algorithms to be able to reach near-optimal solutions into the available time given by the period length.

\section{Appendix I: Linearization of non-linear terms}

Some terms of the constraints shown in Eqs. (43)-(47) are nonlinear. This nonlinearity is due to considering the production planning and scheduling as part of the decision process, requiring the completion time $\left(C R_{r, p, t}\right)$ and the length $\left(L R_{r, p, t}\right)$ of a production run to be decision variables. Each of the nonlinear terms in those constraints is the product of a continuous variable and a binary variable. All these terms can be easily linearized by incorporating some additional non negative real variables defined as in Eq. (A1), (Ghezavati \& Mehrabad, 2010; Chang \& Chang, 2000).

$$
\begin{array}{lll}
C R z u_{i, t, r, p}=C R_{t, r, p} \times z u_{i, t, r, p} & ; & \forall(i, t, r, p) \\
L R z u_{i, t, r, p}=L R_{t, r, p} \times z u_{i, t, r, p} & ; \quad \forall(i, t, r, p) \\
C R z l_{i, t, r, p}=C R_{t, r, p} \times z l_{i, t, r, p} & ; \quad \forall(i, t, r, p) \\
L R z l_{i, t, r, p}=L R_{t, r, p} \times z l_{i, t, r, p} & ; \quad \forall(i, t, r, p)
\end{array}
$$

Furthermore, the constraints shown in Eqs. (A2)-(A5) are needed to make both models, linear and nonlinear, equivalent. $M_{4}$ is a relatively large number, which can be set to $1.1 \times T \times h \max$. Now, the nonlinear constraints shown in Eqs. (43)-(47) can be replaced by the linear ones shown in Eqs. (A6)-(A10).

$$
\begin{array}{ll}
C R z u_{i, t, r, p} \geq C R_{t, r, p}+M_{4} \cdot z u_{i, t, r, p}-M_{4} & ; \forall(i, t, r, p) \\
C R z u_{i, t, r, p} \leq C R_{t, r, p} & ; \forall(i, t, r, p) \\
C R z u_{i, t, r, p} \leq M_{4} \cdot z u_{i, t, r, p} & ; \forall(i, t, r, p) \\
L R z u_{i, t, r, p} \geq L R_{t, r, p}+M_{4} \cdot z u_{i, t, r, p}-M_{4} & ; \forall(i, t, r, p) \\
L R z u_{i, t, r, p} \leq L R_{t, r, p} & ; \forall(i, t, r, p) \\
L R z u_{i, t, r, p} \leq M_{4} \cdot z u_{i, t, r, p} & ; \forall(i, t, r, p) \\
C R z l_{i, t, r, p} \geq C R_{t, r, p}+M_{4} \cdot z l_{i, t, r, p}-M_{4} & ; \forall(i, t, r, p) \\
C R z l_{i, t, r, p} \leq C R_{t, r, p} & ; \forall(i, t, r, p) \\
C R z l_{i, t, r, p} \leq M_{4} \cdot z l_{i, t, r, p} & ; \forall(i, t, r, p) \\
L R z l_{i, t, r, p} \geq L R_{t, r, p}+M_{4} \cdot z l_{i, t, r, p}-M_{4} & ; \forall(i, t, r, p) \\
L R z l_{i, t, r, p} \leq L R_{t, r, p} & ; \forall(i, t, r, p) \\
L R z l_{i, t, r, p} \leq M_{4} \cdot z l_{i, t, r, p} & ; \forall(i, t, r, p) \\
C R z u_{i, t, r, p}-L R z u_{i, t, r, p} \leq C_{i, t} \leq C R_{r, p, t}-L R_{r, p, t}+h m a x \cdot t \cdot z u_{i, t, r, p} \quad ; \quad \forall(i, t, r, p) \\
C R z u_{i, t, r, p} \leq C_{i, t}-L_{i, t} \leq C R_{r, p, t}+h m a x \cdot t \cdot z l_{i, t, r, p} \quad ; \quad \forall(i, t, r, p)
\end{array}
$$




$$
\begin{aligned}
& q u_{i, t, r, p} \leq v r_{p} \cdot L R z u_{i, t, r, p} \quad ; \quad \forall(i, t, r, p) \\
& q u_{i, t, r, p} \leq v r_{p} \cdot\left[C_{i, t}-\left(C R z u_{i, t, r, p}-L R z u_{i, t, r, p}\right)\right] ; \quad \forall(i, t, r, p) \\
& q l_{i, t, r, p} \geq v r_{p} \cdot L R z l_{i, t, r, p} \quad ; \quad \forall(i, t, r, p)
\end{aligned}
$$

\section{Appendix II: Speed-up constraints}

The following set of redundant constraints can be incorporated to the model in order to speed up the branch-and-bound solution algorithm as suggested in Cafaro and Cerdá (2004). They account for the fact that every slug in transit moves along the pipeline when a new slug is pumped. The constraints in Eqs. (A11) and (A12) state that upper coordinates of the slugs are increasing with time. Similarly, lower coordinates of the slugs increase with time as shown in the constraints in Eqs. (A13) and (A14). Finally, Eqs. (A15) and (A16) state that the volume of a slug in pipeline transit is always a lower bound on the value of its upper volumetric coordinate.

$$
\begin{aligned}
& F O_{o, i, t} \geq F O_{o, i-1, t} \quad ; \quad \forall(o, i, t): i>1 \\
& F o_{o, 1, t} \geq F o_{o, I, t-1} \quad ; \quad \forall(o, t): t>1 \\
& F O_{o, 1,1} \geq F 0_{O} \quad ; \quad \forall o \\
& F_{i, t, i^{\prime}, t^{\prime}} \geq F_{i, t, i^{\prime}-1, t^{\prime}} \quad ; \quad \forall\left(i, t, i^{\prime}, t^{\prime}\right): i^{\prime}>1, t<t^{\prime} \\
& F_{i, t, 1, t^{\prime}} \geq F_{i, t, I, t^{\prime}-1} \quad ; \quad \forall\left(i, t, t^{\prime}\right): t<t^{\prime} \\
& F_{i, t, i^{\prime}, t} \geq F_{i, t, i^{\prime}-1, t} \quad ; \quad \forall\left(i, t, i^{\prime}\right): i<i^{\prime} \\
& F o_{o, i, t}-W o_{o, i, t} \geq F o_{o, i-1, t}-F o_{o, i-1, t} \quad ; \quad \forall(o, i, t): i>1 \\
& F o_{o, 1, t}-W o_{o, 1, t} \geq F o_{o, I, t-1}-W o_{o, I, t-1} \quad ; \quad \forall(o, t): t>1 \\
& F o_{o, 1,1}-W o_{o, 1,1} \geq F 0_{O}-W 0_{O} \quad ; \forall o \\
& F_{i, t, i^{\prime}, t^{\prime}}-W_{i, t, i^{\prime}, t^{\prime}} \geq F_{i, t, i^{\prime}-1, t^{\prime}}-W_{i, t, i^{\prime}-1, t^{\prime}} \quad ; \quad \forall\left(i, t, i^{\prime}, t^{\prime}\right): i^{\prime}>1, t<t^{\prime} \\
& F_{i, t, 1, t^{\prime}}-W_{i, t, 1, t^{\prime}} \geq F_{i, t, I, t^{\prime}-1}-W_{i, t, I, t^{\prime}-1} \quad ; \quad \forall\left(i, t, t^{\prime}\right): t<t^{\prime} \\
& F_{i, t, i^{\prime}, t}-W_{i, t, i^{\prime}, t} \geq F_{i, t, i^{\prime}-1, t}-W_{i, t, i^{\prime}-1, t} \quad ; \quad \forall\left(i, t, i^{\prime}\right): i<i^{\prime} \\
& F o_{o, i, t} \geq W o_{o, i, t} \quad ; \quad \forall(o, i, t) \\
& F_{i, t, i^{\prime}, t^{\prime}} \geq W_{i, t, i^{\prime}, t^{\prime}} \quad ; \quad \forall\left(i, t, i^{\prime}, t^{\prime}\right): t<t^{\prime} \\
& F_{I, t, i^{\prime}, t} \geq W_{I, t, i^{\prime}, t} \quad ; \quad \forall\left(i, t, i^{\prime}\right): i \leq i^{\prime}
\end{aligned}
$$

\section{Acknowledgments}

This research is supported by Discovery Grant from NSERC of Canada, Faculty Research Support Fund from the Faculty of Engineering and Computer Science, Concordia University, and the Spanish MCYT, "Ministerio de Ciencia y Tecnología", under Grant BES-2003-0958 (project DPI2002-02924). 


\section{References}

Cafaro, D. C. \& Cerdá, J., (2003). A continuous-time approach to multiproduct pipeline scheduling. Computer-Aided Chemical Engineering, 65-73.

Cafaro, D. C. \& Cerdá, J., (2004). Optimal scheduling of multiproduct pipeline systems using a nondiscrete MILP formulation. Computers and Chemical Engineering, 28, 2053-2068.

Cafaro, D. C. \& Cerdá J. (2008). Dynamic scheduling of multiproduct pipelines with multiple delivery due dates. Computers and Chemical Engineering, 32, 728-753.

Camacho, E. F., Ridao M. A., Ternero, J. A. \& Rodríguez, J. M. (1990). Optimal operation of pipeline transportation systems. Control of Transportation Systems, 5, 455-460.

Camponogara, E. \& De Souza, P.S., (1996). A-Teams for oil transportation problem through pipelines. Information Systems Analysis and Synthesis, Proceedings of the International Conference of Information Systems Analysis and Synthesis, Orlando, 718-725.

Chang, C. T., \& Chang, C. C., (2000). A linearization method for mixed 0-1 polynomial programs. Computers \& Operations Research, 27, 1005-1016.

Cruz, J. M, Andrés, B., Herrán, A., Besada, E. \& Fernández, P. (2003). Multiobjective optimization of the transport in oil pipelines networks. 9th IEEE International Conference on Emerging Technologies and Factory Automation, 1, 566-573.

Cruz, J. M., Risco J. L., Herrán A. \& Fernández P. (2004). Hybrid heuristic and mathematical programming in oil pipelines networks. Congress on evolutionary computation CEC2004, 1, 1479-1486.

Cruz, J. M., Herrán, A., Risco J. L. \& Andrés B. (2005). Hybrid heuristic and mathematical programming in oil pipelines networks: use of inmigrants. Journal of Zhejiang University SCIENCE. 6A(1), 9-19.

De Felice, C.A., (1975). A discrete deterministic pipeline flow simulation with online scheduler interface to solve dynamic bach scheduling problems. Winter Computer Simulation Conference.

Defersha, F. M., Herrán A., Chen, M. \& de la Cruz, J. M., (2008). A mathematical model for an integrated multi-period lanning of the production and transportation of multiple petroleum products in a pipeline system. In the proceeding of the Sixth annual International Symposium on Supply Chain Management, 143-160.

Ghezavati, V. R. \& Saidi Mehrabad, M. (2010). An efficient linearization technique for mixed 0-1 polynomial problems. Journal of Computational and Applied Mathematics. Article in Press, doi:10.1016/j.cam.2010.08.009.

Hane, C. A. \& Ratliff H. D. (1993). Sequencing inputs to multi-commodity pipelines. Annals of Operations Research, 57, 77-109.

ILOG Inc., (2003). ILOG OPL Studio 3.6 Users Manual, http://www.ilog.com, 1080 Linda Vista Ave. Mountain View, CA 94043.

Magatao, L., Arruda, L.V. \& Neves, Jr F., (2004). A mixed integer programming approach for scheduling commodities in a pipeline. Computers \& Chemical Engineering, 28, 171-185.

Milidú, R. L., Pessoa A. A., \& Laber E. S., (2002). Pipeline transportation of petroleum with no due dates. Proceedings of the 5th Latin American Symposium on Theoretical Informatics, 248-262.

Mirhassani, S.A., \& Ghorbanalizadeh, M. (2008). The multiproduct pipeline scheduling system. Computers and Mathematics with Applications, 56(4), 891-897.

Rejowski, Jr. R. \& Pinto, J.M. (2003). Scheduling of a multiproduct pipeline system. Computers and Chemical Engineering, 27, 1229-1246.

Rejowski, Jr. R. \& Pinto, J.M. (2004). Efficient MILP formulations and valid cuts for multiproduct pipeline scheduling. Computers and Chemical Engineering, 28, 1511-1528.

Rejowski, Jr R., \& Pinto J.M. (2008). A novel continuous time representation for the scheduling of pipeline systems with pumping yield rate constraints. Computers and Chemical Engineering, 32, $1042-1066$. 
Sasikumar, M., Prakash, P.R., Patil, S.M. \& Ramani, S. (1997). PIPES: A heuristic search model for pipeline schedule generation. Knowledge-Based Systems, 10, 169-175.

Techo, R. \& Holbrook, D.L. (1974). Computer scheduling the worlds' biggest product pipeline. Pipeline and Gas Journal, 4, 4-27. 